\title{
Determination of Rate Parameters Based on Both Direct and Indirect Measurements
}

\author{
T. TURÁNYI, ${ }^{1}$ T. NAGY, ${ }^{1}$ I. GY. ZSÉLY, ${ }^{1}$ M. CSERHÁTI, ${ }^{1}$ T. VARGA, ${ }^{1}$ B. T. SZABÓ,${ }^{2}$ \\ I. SEDYÓ, ${ }^{1}$ P. T. KISS, ${ }^{1}$ A. ZEMPLÉNI, ${ }^{3}$ H. J. CURRAN ${ }^{4}$ \\ ${ }^{1}$ Institute of Chemistry, Eötvös University (ELTE), H-1518 Budapest, Hungary \\ ${ }^{2}$ Technische Universiteit Eindhoven, Eindhoven, The Netherlands \\ ${ }^{3}$ Department of Probability Theory and Statistics, Eötvös University (ELTE), H-1518 Budapest, Hungary \\ ${ }^{4}$ Combustion Chemistry Centre, National University of Ireland Galway, Galway, Ireland
}

Received 1 June 2011; revised 28 November 2011; accepted 2 January 2012

DOI 10.1002/kin.20717

Published online 23 February 2012 in Wiley Online Library (wileyonlinelibrary.com).

\begin{abstract}
The determination of rate parameters of gas-phase elementary reactions is usually based on direct measurements. The rate parameters obtained in many independent direct measurements are then used in reaction mechanisms, which are tested against the results of indirect experiments, like time-to-ignition or laminar flame velocity measurements. We suggest a new approach that takes into account both direct and indirect measurements and optimizes all influential rate parameters. First, the domain of feasibility of the Arrhenius parameters is determined from all of the available direct measurements. Thereafter, the optimal Arrhenius parameters are sought within this domain to reproduce the selected direct and indirect measurements. Other parameters of a complex mechanism (third-body efficiencies, enthalpies of formation, parameters of pressure dependence, etc.) can also be taken into account in a similar way. A new fitting algorithm and a new method for error calculation were developed to determine the optimal mean values and the covariance matrix of all parameters. The approach is demonstrated on the calculation of Arrhenius parameters of reactions (R1): $\mathrm{H}+\mathrm{O}_{2}=$ $\mathrm{OH}+\mathrm{O}$ and (R2): $\mathrm{H}+\mathrm{O}_{2}+\mathrm{M}=\mathrm{HO}_{2}+\mathrm{M}$ (low-pressure limit, $\mathrm{M}=\mathrm{N}_{2}$ or Ar). In total, 9 direct measurements for reaction (R1) (745 data points), 10 direct measurements for reaction (R2) ( 258 data points), and 11 ignition time measurements (79 data points) were taken into account. The application of the method resulted in the following rate parameters for the investigated reactions-(R1): $\mathrm{A}=3.003 \times 10^{10} \mathrm{~cm}^{3} \mathrm{~mol}^{-1} \mathrm{~s}^{-1}, n=0.965, \mathrm{E} / \mathrm{R}=6158 \mathrm{~K}(\mathrm{~T}=950-3550 \mathrm{~K})$
\end{abstract}

\footnotetext{
Correspondence to: Tamás Turányi; e-mail: turanyi@chem .elte.hu.

Contract grant sponsor: OTKA.

Contract grant number: T84054.

Contract grant number: NN100523.

Contract grant sponsor: The European Union and the European Social Fund

Contract grant number: TÁMOP-4.2.1/B-09/1/KMR.

(c) 2012 Wiley Periodicals, Inc.
} 


\begin{abstract}
and (R2): $A=7.856 \times 10^{18} \mathrm{~cm}^{6} \mathrm{~mol}^{-2} \mathrm{~s}^{-1}, n=-1.100, \mathrm{E} / \mathrm{R}=0 \mathrm{~K}$ (low-pressure limit, $\mathrm{M}=\mathrm{N}_{2}, \mathrm{~T}=300-1850 \mathrm{~K}$ ). The optimized third-body efficiency of Ar relative to $\mathrm{N}_{2}$ is $m=0.494$ (standard deviation $\sigma=0.010$ ). The uncertainty parameter $f$ as a function of temperature was also calculated. Average uncertainty parameter values are $f=0.025$ and 0.049 for reactions (R1) and (R2) (corresponding to $6 \%$ and $12 \%$ ), respectively, which are much lower than those of the previous evaluations. (C) 2012 Wiley Periodicals, Inc. Int J Chem Kinet 44: 284-302, 2012
\end{abstract}

\section{INTRODUCTION}

Traditionally, direct and indirect chemical kinetic measurements have been distinguished. In direct measurements, the reaction conditions are selected in such a way that the measured signal depends mainly on the rate parameters of a single reaction step, thus a rate coefficient can be determined from it directly. In the indirect measurements, the experimental results depend on the rate parameters of several elementary reactions and these data can be interpreted via simulations using a detailed reaction mechanism. These studies are also called bulk measurements. In combustion chemistry, examples for the indirect studies are ignition time and laminar flame velocity measurements. In some cases, direct and indirect measurements cannot be distinguished clearly. For example, in several shock tube measurements, the aim is the determination of the rate parameters of a single elementary reaction, but the evaluation is based on a small reaction mechanism and the results also depend on the assumed rate parameters of the other reaction steps.

Determination of the rate parameters of detailed reaction mechanisms is usually based on direct kinetic measurements. If direct measurements are not available, the rate coefficients are estimated by theoretical calculations or analogies. Comprehensive data evaluations based on direct measurements have been published by Baulch et al. [1-3]. For many gas-phase elementary reactions, the rate coefficients have been measured by several groups and at a given temperature, the rate coefficients typically have an uncertainty of $\pm 10 \%$ to $\pm 30 \%$, even for the best-known reactions. Miller et al. [4] pointed to the fact that repeated direct measurements of the rate parameters of important reactions, even performed independently by several groups, did not decrease the uncertainty of the rate coefficients below a certain limit. The struggle for the determination of precise rate constants was demonstrated by Miller et al. using the reaction $\mathrm{H}+\mathrm{O}_{2}=\mathrm{OH}+\mathrm{O}$ as an example. Their review also discussed the case of the reaction $\mathrm{H}+\mathrm{O}_{2}+\mathrm{M}=\mathrm{HO}_{2}+\mathrm{M}$. The uncertainty of the rate coefficients of these reactions was estimated to be about $30 \%$ and $50 \%$, respectively.

When the rate parameters determined in direct measurements are used in a detailed reaction mechanism, the kinetic model usually does not reproduce well the results of indirect measurements. This is due to the relatively large uncertainty of the rate coefficients. In almost all mechanisms suggested in the literature, some of the rate parameters have been tuned to reproduce the indirect experimental data. A more systematic approach was proposed by Frenklach and his coworkers, who suggested fitting of the $A$ factors of the most important reaction steps to the results of selected indirect measurements.

The first articles on the topic of mechanism optimization were written by Miller and Frenklach [5,6] in the early 1980s. The basic method was described in 1992 in the article of Frenklach et al. [7]. This method was used for the creation of the GRI mechanisms, which describe the combustion of methane and $\mathrm{NO}_{x}$ formation during methane combustion. The first versions of the GRI mechanism (such as GRIMech 1.2 [8] and GRI-Mech 2.11 [9]) were replaced in 1999 with GRI-Mech 3.0 [10], which is the latest version. GRI-Mech 3.0 served as an example of data collaboration studies in the papers of Frenklach et al. [11-18]. Another series of mechanism optimization papers were published by Wang et al. They optimized combustion mechanisms of other fuels, such as propane [19], $\mathrm{H}_{2} / \mathrm{CO}$ mixtures [20], ethylene [21], and $n$-heptane [22]. The Wang et al. articles dealt with the improvement of the optimization methodology [23] and investigated the relation of mechanism optimization and uncertainty analysis of combustion simulations [21,22,24].

The mechanism optimization methodology of the authors above can be summarized as follows: A starting mechanism is parameterized on the basis of data evaluations. Then, 12-80 indirect measurement data (called "optimization targets") are selected. These data included laminar flame velocity, time to ignition, and concentration measurements in flames and flow reactors. Using local sensitivity analysis, the important reactions at the experimental conditions are identified. The $A$ factors of the important reactions (and certain enthalpies of formation and third-body efficiencies) are called active parameters by these authors. The uncertainty limits of the $A$ factors are determined on the basis of the $f$ uncertainty parameters of the data evaluations, and the active parameters are optimized within the 
uncertainty limits to achieve the best agreement with the targets.

A drawback of this method was that the optimized $A$ factors tended to move to the edges of the uncertainty interval. To overcome this problem, in the recent works of Frenklach et al. [18] and Sheen and Wang [22], the objective function was extended in such a way that deviation from the evaluated $A$ factor (determined on the basis of direct measurements) was also penalized. This approach resulted in optimized $A$ factors closer to the evaluated values. In the latest works of Frenklach et al. and Wang et al., the uncertainties of both the determined parameters and the simulation results are investigated $[18,21,24]$.

Note that a similar idea of optimizing physical parameters using many measured or theoretically calculated data has been used for the determination of enthalpies of formation in the Active Thermochemical Table approach of Ruscic et al. $[25,26]$ and in the NEAT method of Császár and Furtenbach [27].

Scire et al. [28] proposed a method for the derivation of the rate coefficients by fitting parameters of a complex reaction mechanism to experimental data. They suggested importance-sampled Monte Carlo calculations, in which the parameter values were distributed according to their uncertainties. The method provided not only optimized rate coefficients but also rigorous error estimates.

The methodology used in this paper shows similarities with the works cited above, with several differences. In our work, experimental results of direct measurements are taken into account directly and not via an evaluated value based on the direct measurements. The original indirect measurement data are used instead of a "target value" deduced from a series of indirect measurements at given conditions. The joint uncertainty domain of all Arrhenius parameters is determined here and not only the uncertainty limits of the $A$ factors. Also, all Arrhenius parameters and other influential rate parameters of the important reactions are optimized, not just the $A$ factors. Our approach is demonstrated by the determination of the Arrhenius parameters of reactions (R1): $\mathrm{H}+\mathrm{O}_{2}=\mathrm{OH}+\mathrm{O}$ and (R2): $\mathrm{H}+\mathrm{O}_{2}+\mathrm{M}=\mathrm{HO}_{2}+\mathrm{M}$ (low-pressure limit, $\mathrm{M}=\mathrm{N}_{2}$ ) and the third-body efficiency $m$ of Ar relative to $\mathrm{N}_{2}$ in reaction (R2).

\section{DETERMINATION OF RATE PARAMETERS USING BOTH DIRECT AND INDIRECT MEASUREMENTS}

At any temperature, direct measurements define the range of uncertainty that contains the "true" value of the rate coefficient. Using several direct measurements at different temperatures, the uncertainty band of the rate coefficient as a function of temperature can be determined. In a similar way, high-level theoretical methods can also determine the range of uncertainty of the rate coefficients. Unfortunately, this uncertainty band is rather wide and reproduction of the results of indirect measurements requires much better known rate coefficients. On the other hand, indirect measurements alone cannot be used for the determination of the rate parameters. Reproduction of the result of an indirect measurement requires simulations with a detailed reaction mechanism. In this mechanism, usually the rate parameters of 2-10 reactions are critical. Also, the result of an indirect experiment (e.g., time-to-ignition or laminar flame velocity) usually does not belong to a single temperature, but to a range of temperatures; therefore, the temperature dependencies of the rate coefficients have to be taken into account. If only the direct measurements are used for the determination of the uncertainty band of the rate coefficients, then a great part of the experimental data available in the literature are not taken into account.

These features of the direct and indirect measurements suggest an algorithm, in which the rate parameters are looked for in their uncertainty range, ensuring that the determined parameters are physically meaningful. All experimental data belonging to a group of reactions are taken into account. The background of the approach is that all indirect measurements can be interpreted on the basis of the same complex mechanism.

Determination of the rate parameters of elementary reactions using both direct and indirect measurements may be based on the following algorithm:

i. Simultaneous selection of the parameters to be determined and the set of indirect measurements. Large amount of experimental data of indirect measurements are collected and simulated using a complex reaction mechanism. A sensitivity analysis is carried out with respect to the measured signals. Simulated indirect measurement data are identified, which are very sensitive to the rate parameters of a small group of reactions and insensitive to all other parameters. The rate parameters of these reactions can be determined by using the corresponding indirect measurements as fitting targets.

ii. Collection of the direct measurements. Experimental data belonging to the direct measurements for the determination of the rate coefficients of the selected reactions are collected. In the past few decades, the articles list the values of the measured rate coefficients as a function of temperature, pressure, bath gas, and maybe other 
reaction conditions. Using the original measured signal for parameter estimation would be better, but such data are generally not available at present.

iii. Estimation of the probability density function and the uncertainty domain of the Arrhenius parameters. The $k^{\mathrm{min}}$ and $k^{\max }$ values of the rate coefficients at several temperatures in the range of interest are determined from the results of direct measurements. Then, using the method of Nagy and Turányi [29], the corresponding approximate $p d f$ of the Arrhenius parameters and $k^{\min }(T)$ and $k^{\max }(T)$ curves are constructed. The $p d f$ is truncated by setting its value to zero at those Arrhenius parameter combinations where the corresponding $k(T)$ curve falls outside the range of $k^{\min }(T)$ and $k^{\max }(T)$. The range of uncertainty of other rate parameters to be optimized should also be determined from direct measurements or from theoretical considerations.

iv. Determination of the optimal set of parameters and the joint covariance matrix of all optimized parameters. An objective function that measures the agreement between the experimental and the simulated results is defined. Using an appropriate global optimization method, the optimal parameter set is determined, and the covariance matrix of the parameters is estimated. The aim is the determination of the "real" physical values of the rate parameters, not just a set of parameters that reproduce well the actually selected indirect measurements. However, it is natural that adding more experimental data slightly changes the estimation of the optimal parameter set and its uncertainty.

The recommended rate parameters in the chemical kinetic databases are based on direct measurements or theoretical calculations related to individual reactions; therefore, the databases assign a separate uncertainty limit for the parameters of each reaction step. This approach means that the uncertainty limits belonging to a rate coefficient are independent of the assumed rate coefficient values of the other reaction steps. While the determination of the rate parameters via simultaneous consideration of both direct and indirect measurements can reduce the uncertainty of the parameters, it inherently introduces correlation among the parameters. Instead of using an independent uncertainty measure for each parameter, the covariance matrix of the parameters can be used for a more accurate uncertainty analysis study of models based on detailed chemical kinetic mechanisms.

\section{ESTIMATION OF THE UNCERTAINTY DOMAIN OF THE ARRHENIUS PARAMETERS}

Collections of evaluated data in atmospheric and combustion chemistry characterize the uncertainty of the rate coefficient at a given temperature by uncertainty parameter $f$. Nagy and Turányi in a recent article [29] provided a detailed discussion of the meaning of this parameter in the various databases. In combustion chemistry, the uncertainty factor $f$ at temperature $T$ is defined in the following way:

$$
\begin{aligned}
f(T) & =\log _{10}\left(k^{0}(T) / k^{\min }(T)\right) \\
& =\log _{10}\left(k^{\max }(T) / k^{0}(T)\right)
\end{aligned}
$$

where $k^{0}$ is the recommended value of the rate coefficient and values below $k^{\text {min }}$ and above $k^{\text {max }}$ are considered to be very improbable. Assuming that the minimum and maximum values of the rate coefficients correspond to $m_{f} \times \sigma$ deviations from the recommended values on a logarithmic scale, the uncertainty factor $f$ can be converted [32] to the standard deviation of the logarithm of the rate coefficient at a given temperature $T$ using the equation

$$
\sigma(\ln k)=\ln 10 \times \sigma\left(\log _{10} k\right)=\frac{\ln 10}{m_{f}} f(T)
$$

The usual assumptions are $3 \sigma$ deviations [30-36] or $2 \sigma$ deviations $[21,22]$; therefore, $m_{f}=3$ or 2 , respectively. Note that assuming $3 \sigma$ deviations instead of $2 \sigma$ deviations means that smaller variance of $\ln k$ is assumed to the same $k^{\text {min }}$ and $k^{\text {max }}$ limits. In this work, $3 \sigma$ deviations $\left(m_{f}=3\right)$ are assumed.

The temperature dependence of the rate coefficient $k$ can be described by the modified Arrhenius equation, $k=A\{T\}^{n} \exp (-E / R T)$. The operator \{\} results in the dimensionless value of a physical quantity at known units. By introducing transformed parameters $\kappa(T)=$ $\ln \{k(T)\}, \alpha=\ln \{A\}$, and $\varepsilon=E / R$, the linearized form of the modified Arrhenius equation is

$$
\kappa(T)=\alpha+n \ln \{T\}-\varepsilon T^{-1}
$$

The following relation can be deduced [29] between the variance of $\kappa$ and the elements of the covariance matrix of $\alpha, n$, and $\varepsilon$ :

$$
\begin{aligned}
\sigma_{\kappa}^{2}(T)= & \sigma_{\alpha}^{2}+\sigma_{\varepsilon}^{2} T^{-2}+\sigma_{n}^{2} \ln ^{2} T-2 r_{\alpha \varepsilon} \sigma_{\alpha} \sigma_{\varepsilon} T^{-1} \\
& -2 r_{\varepsilon n} \sigma_{\varepsilon} \sigma_{n} T^{-1} \ln T+2 r_{\alpha n} \sigma_{\alpha} \sigma_{n} \ln T
\end{aligned}
$$

If the variance of $\kappa$ is known for at least six temperatures, the six parameters of the covariance matrix 
(standard deviations $\sigma_{\alpha}, \sigma_{n}$, and $\sigma_{\varepsilon}$ and correlation coefficients $r_{\alpha n}, r_{\alpha \varepsilon}$, and $r_{n \varepsilon}$ ) can be determined by parameter fitting, taking into account also the following constraints:

$$
\begin{gathered}
0 \leq \sigma_{\alpha}, \sigma_{n}, \sigma_{\varepsilon} \\
-1 \leq r_{\alpha n}, r_{\alpha \varepsilon}, r_{n \varepsilon} \leq+1 \\
0 \leq 1-r_{\alpha n}^{2}-r_{\alpha \varepsilon}^{2}-r_{n \varepsilon}^{2}+2 r_{\alpha n} r_{\alpha \varepsilon} r_{n \varepsilon}
\end{gathered}
$$

The last constraint comes from the fact that the correlation matrix is per definitionem positive semidefinite. It is recommended to use uncertainty data at more than six temperatures for the determination of the covariance matrix. Note that Hébrard et al. [37] recommended an expression similar to Eq. (4) for the traditional (two-parameter) Arrhenius equation to characterize the temperature dependence of the uncertainty of the rate coefficients.

The uncertainty parameter $f$ can be obtained from data evaluations. Unfortunately, for many reactions, this parameter is declared to be temperature independent, which is equivalent to the (physically not realistic) statement that only the Arrhenius parameter $A$ has uncertainty and parameters $n$ and $E$ are known with infinite precision [29]. For other reactions, an approximate temperature dependence of parameter $f$ is defined. However, based on an evaluation of the available experimental data and theoretical results, it is possible to define $k^{\min }(T)$ and $k^{\max }(T)$ limits to the rate coefficient of an elementary reaction. This allows the estimation of function $f(T)$ using Eq. (1) and the determination of the uncertainty domain of the transformed Arrhenius parameters $\alpha, n$, and $\varepsilon$ using Eqs. (4) and (5). If experimental information is not available, in most cases, a wider domain of uncertainty can be found using the rate theories of chemical reactions.

\section{DETERMINATION OF THE OPTIMAL SET OF PARAMETERS}

Experimental information about a set of reactions includes the results of both direct and indirect measurements. The preceding section described the determination of the domain of uncertainty of the rate parameters on the basis of the results of direct measurements. All parameter values within this domain are possible on the basis of the results of direct measurements. However, some parameter values provide simulation results that are in better accordance with the results of indirect measurements. Also, using only the results of the indirect measurements means that a great part of the available experimental data is not used. Therefore, to find the optimal set of parameters, both types of experimental data should be taken into account. This optimal parameter set belongs to the minimum of an objective function, which characterizes the deviation between model results and experimental data. The optimal parameter set depends on the selection of the objective function; therefore, much attention has to be paid to the definition of this function.

\section{Definition of the Objective Function}

The following objective function is used in our calculations:

$$
E(\mathbf{p})=\sum_{i=1}^{N} E_{i}(\mathbf{p})=\sum_{i=1}^{N} \frac{w_{i}}{N_{i}} \sum_{j=1}^{N_{i}}\left(\frac{Y_{i j}^{\bmod }(\mathbf{p})-Y_{i j}^{\exp }}{\sigma\left(Y_{i j}^{\exp }\right)}\right)^{2}
$$

where

$$
Y_{i j}= \begin{cases}y_{i j} & \text { if } \sigma\left(y_{i j}^{\exp }\right) \approx \text { constant } \\ \ln y_{i j} & \text { if } \sigma\left(\ln y_{i j}^{\exp }\right) \approx \text { constant }\end{cases}
$$

where $\mathbf{p}=\left(p_{1}, p_{2}, \ldots, p_{n_{\mathrm{p}}}\right)$ is the vector of parameters. Parameter vector $\mathbf{p}$ includes the Arrhenius parameters of the selected reactions, and it may contain other rate parameters such as branching ratios, thirdbody efficiencies, parameters describing the pressure dependence (e.g., Troe or SRI parameters), and thermodynamic data.

The published results of direct measurements include rate coefficients $k$ measured at given conditions (e.g., temperature, pressure, and bath gas). In the case of indirect measurements, the results are data such as ignition delay times and/or laminar flame velocities. In Eq. (6), $N$ is the number of measurement series (direct and indirect together) and $N_{i}$ is the number of data points in the $i$ th measurement series. Value $y_{i j}^{\exp }$ is the $j$ th data point in the $i$ th measurement series. The corresponding modeled value $y_{i j}^{\text {mod }}(\mathbf{p})$ for parameter set $\mathbf{p}$ can be obtained by calculating the rate coefficient at the given temperature (and pressure, bath gas, etc.) or by carrying out a simulation with combustion kinetic codes using an appropriate detailed mechanism. The objective function is the sum of the partial objective functions $E_{i}(\mathbf{p})$, which belong to the various measurement series.

The form of the objective function includes automatic weighting according to the number of data points and the standard deviation of the data. Normalization with the number of data points $\left(N_{i}\right)$ is necessary to prevent bias toward data series with a large number of points, and considering the experimental standard deviation $\sigma\left(Y_{i j}^{\exp }\right)$ is necessary to prevent bias toward measured data points with large errors. 
Additional individual weighing $w_{i}$ of the $i$ th measurement series can also be taken into account according to the consideration of the user. Users of the method might want to emphasize some measurements or decrease the weight of others. Also, these numbers can be used to set the equal weighting of some types of measurements, e.g., setting equal influence of flame velocity and ignition time measurements despite the different number of experimental data series available. In our current calculations, all data series were weighted equally $\left(w_{i}=1\right)$.

The objective function can be transformed into a simpler form by introducing a single index $k$, which runs through all data points of all measurement series. A new unified weight $\mu_{k}=w_{k} / N_{k}$ is used for each data point, which further simplifies the objective function:

$$
E(\mathbf{p})=\sum_{k=1}^{N} \mu_{k}\left(\frac{Y_{k}^{\bmod }(\mathbf{p})-Y_{k}^{\exp }}{\sigma\left(Y_{k}^{\exp }\right)}\right)^{2}
$$

This equation can be condensed by introducing matrixvector notation:

$$
E(\mathbf{p})=\left(\mathbf{Y}_{\bmod }(\mathbf{p})-\mathbf{Y}_{\exp }\right)^{\mathrm{T}} \mathbf{W} \boldsymbol{\Sigma}_{\mathbf{Y}}^{-1}\left(\mathbf{Y}_{\bmod }(\mathbf{p})-\mathbf{Y}_{\exp }\right)
$$

Here, $\mathbf{Y}_{\bmod }(\mathbf{p})$ and $\mathbf{Y}_{\exp }$ denote the column vectors formed from values of $Y_{k}^{\bmod }(\mathbf{p})$ and $Y_{k}^{\exp }$.

$$
\begin{aligned}
\mathbf{Y}_{\bmod }(\mathbf{p}) & =\left(Y_{1}^{\bmod }(\mathbf{p}) \cdots Y_{N}^{\bmod }(\mathbf{p})\right)^{T}, \\
\mathbf{Y}_{\exp } & =\left(Y_{1}^{\exp } \cdots Y_{N}^{\exp }\right)^{T}
\end{aligned}
$$

Matrices $\mathbf{W}$ and $\boldsymbol{\Sigma}_{\mathbf{Y}}$ are the diagonal matrices of weights $\mu_{k}$ and variances $\sigma^{2}\left(Y_{k}^{\exp }\right)$, respectively. The diagonal matrix $\boldsymbol{\Sigma}_{\mathbf{Y}}$ is the covariance matrix of vector $\mathbf{Y}_{\text {exp }}$. Its elements are assumed to be uncorrelated because of the lack of any information on the statistical correlation among the data points $Y_{k}^{\exp }$.

$$
\begin{aligned}
\mathbf{W} & =\operatorname{diag}\left(\mu_{1}, \mu_{2}, \ldots, \mu_{\mathrm{N}}\right) \\
\boldsymbol{\Sigma}_{\mathbf{Y}} & =\frac{\Delta \mathbf{Y}_{\exp } \Delta \mathbf{Y}_{\exp }^{\mathrm{T}}}{} \\
& =\operatorname{diag}\left(\sigma^{2}\left(Y_{1}^{\exp }\right), \sigma^{2}\left(Y_{2}^{\exp }\right), \ldots, \sigma^{2}\left(Y_{N}^{\exp }\right)\right)
\end{aligned}
$$

\section{The Fitting Procedure}

The optimization procedure starts from the initial values, $\mathbf{p}^{(0)}$, of the parameters, and it is carried out in an iterative manner. We denote $\mathbf{p}^{(i)}$ the best parameter set after the $i$ th optimization cycle. The initial covariance matrix is $\boldsymbol{\Sigma}_{\mathbf{p}}^{(0)}$, which determines the uncertainty domain and the initial Gaussian $p d f$ of the parameters. Counter $n_{c}$ monitors the convergence of the solution and its initial value is zero.
1. In the $i$ th iteration step, based on the $(i-1)$ th approximate Gaussian $p d f$ of the parameters, $s$ parameter sets are generated within the $(i-1)$ th uncertainty domain defined by the $p d f$. This Gaussian $p d f$ is centered on parameter set $\mathbf{p}^{(i-1)}$, and it is fully determined by the $(i-1)$ th reduced covariance matrix, $\tilde{\mathbf{\Sigma}}_{\mathbf{p}}^{(i-1)}$. The reduced covariance matrix is calculated from the $(i-1)$ th covariance matrix $\Sigma_{\mathbf{p}}^{(i-1)}$ by dividing it with $s^{2 n_{\mathrm{c}} / n_{\mathrm{p}}}$, where $n_{p}$ is the number of fitted parameters. Increasing $n_{c}$ by one implies the contraction of the characteristic volume (i.e., the product of the standard deviations) of the sampling Gaussian distribution by a factor of $s$.

2. The objective function value $E\left(\mathbf{p}_{j}\right)$ is calculated for each $\mathbf{p}_{j}$ parameter set, and the one with the smallest $E\left(\mathbf{p}_{j}\right)$ value is selected.

3. If the objective function belonging to the selected parameter set is larger than $E\left(\mathbf{p}^{(i-1)}\right)$, then the counter $n_{c}$ is increased by one (the searching volume is decreased) and $\mathbf{p}^{(i)}$ is set equal to $\mathbf{p}^{(i-1)}$ (the previously found best parameter set is kept). In the opposite case, $\mathbf{p}^{(i)}$ is set to the selected set (a better parameter set was found) and the counter $n_{c}$ is reduced by one (the searching volume is increased).

4. The covariance matrix $\boldsymbol{\Sigma}_{\mathbf{p}}^{(i)}$ of parameter set $\mathbf{p}^{(i)}$ is estimated as described in the next section.

5. If the characteristic sampling range in each dimension is reduced by a factor $10^{5}$, then the fitting procedure is terminated. This is equivalent to when value $s^{n_{\mathrm{c}}} / n_{\mathrm{p}}$ becomes larger than $10^{5}$, that is $n_{c}$ becomes larger than $5 n_{p} \times \log _{s} 10$. Otherwise, the procedure is repeated from step 1 .

\section{Determination of the Covariance Matrix of the Parameters}

Calculation of the covariance matrix of the parameters is needed for two reasons. In each step, the fitting procedure is looking for the optimum value of the parameters in a domain that is determined by the current estimated covariance matrix of the parameters. At the end of model optimization, the covariance matrix calculated at the optimum parameter set is an important result, because it characterizes the uncertainty of the determined parameters.

Differentiation of the objective function (8) with respect to the parameters yields

$$
E^{\prime}(\mathbf{p})=2 \mathbf{J}^{\mathrm{T}} \mathbf{W} \Sigma_{\mathbf{Y}}^{-1}\left(\mathbf{Y}_{\bmod }-\mathbf{Y}_{\exp }\right)
$$


Here $\mathbf{J}$ is the Jacobian, that is, the derivative matrix of $\mathbf{Y}_{\text {mod }}$ with respect to $\mathbf{p}$ :

$$
\mathbf{J}=\mathbf{Y}_{\bmod }^{\prime}(\mathbf{p})
$$

Optimal values of the model parameters are those that provide the global minimum of the objective function within their physically reasonable uncertainty domain. The local minima of the objective function can be found by equaling its derivative $E^{\prime}(\mathbf{p})$ with zero and solving it for $\mathbf{p}$ :

$$
2 \mathbf{J}^{\mathrm{T}} \mathbf{W} \Sigma_{\mathbf{Y}}^{-1}\left(\mathbf{Y}_{\text {mod }}-\mathbf{Y}_{\exp }\right)=\mathbf{0}
$$

Rearranging this equation gives

$$
2 \mathbf{J}^{\mathrm{T}}(\mathbf{p}) \mathbf{W} \Sigma_{\mathbf{Y}}^{-1} \mathbf{Y}_{\bmod }(\mathbf{p})=2 \mathbf{J}^{\mathrm{T}}(\mathbf{p}) \mathbf{W} \Sigma_{\mathbf{Y}}^{-1} \mathbf{Y}_{\exp }
$$

It can be simplified by introducing notation $\mathbf{A}(\mathbf{p})=$ $\mathbf{J}^{\mathrm{T}}(\mathbf{p}) \mathbf{W} \Sigma_{\mathbf{Y}}^{-1}$ :

$$
\mathbf{A}(\mathbf{p}) \mathbf{Y}_{\bmod }(\mathbf{p})=\mathbf{A}(\mathbf{p}) \mathbf{Y}_{\exp }
$$

Solving the nonlinear equation (16) for $\mathbf{p}$ provides a local minimum of the objective function, which is denoted with $\mathbf{p}_{\mathrm{o}}$. The parameter $\mathbf{p}_{\mathrm{o}}$ is always uncertain, as there are systematic discrepancies between the experimental and the modeled results, and also the experimental data has some random scatter $\left(\Delta \mathbf{Y}_{\exp }=\right.$ $\mathbf{Y}_{\text {exp }}-\overline{\mathbf{Y}}_{\text {exp }}$ ) around their expected value $\overline{\mathbf{Y}}_{\text {exp }}$. Assuming the lack of systematic error and only small symmetric scatter of the parameters around the optimal value, their expectation value $(\overline{\mathbf{p}})$ and the optimal value $\left(\mathbf{p}_{\mathrm{o}}\right)$ will coincide, that is $\overline{\mathbf{p}}=\mathbf{p}_{\mathrm{o}}$. Owing to the uncertainty of the model parameters, the model results will also have a random scatter $\left(\Delta \mathbf{Y}_{\text {mod }}=\mathbf{Y}_{\text {mod }}(\mathbf{p})-\overline{\mathbf{Y}}_{\text {mod }}\right)$ around their expectation value $\overline{\mathbf{Y}}_{\text {mod }}$. Assuming linear error propagation, the expectation value of $\mathbf{Y}_{\bmod }(\mathbf{p})$ is equal to the simulation results corresponding to the optimal parameter value, that is $\overline{\mathbf{Y}}_{\text {mod }}=\mathbf{Y}_{\bmod }(\overline{\mathbf{p}})$. The systematic discrepancy $\Delta \overline{\mathbf{Y}}$ between the model and the experimental results $\left(\Delta \overline{\mathbf{Y}}=\overline{\mathbf{Y}}_{\text {mod }}-\overline{\mathbf{Y}}_{\text {exp }}\right)$ is equal to the difference of the systematic errors of the model $\left(\overline{\mathbf{Y}}_{\text {mod }}-\mathbf{Y}_{\text {exact }}\right.$, where $\mathbf{Y}_{\text {exact }}$ is the exact value) and those of the measurements $\left(\overline{\mathbf{Y}}_{\exp }-\mathbf{Y}_{\text {exact }}\right)$. A simple relationship between the expectation value $\overline{\mathbf{Y}}_{\text {mod }}$ and the systematic deviation $\Delta \overline{\mathbf{Y}}$ is the following:

$$
\overline{\mathbf{Y}}_{\text {mod }}=\overline{\mathbf{Y}}_{\exp }+\Delta \overline{\mathbf{Y}}
$$

The coefficient matrix $\mathbf{A}$ has value $\mathbf{A}_{o}$ in the local minimum $\mathbf{p}_{\mathrm{o}}$, and Eq. (16) can be used to estimate the scatter of the parameters around $\mathbf{p}_{\mathrm{o}}$ based on the scatter of experimental results:

$$
\mathbf{A}_{\mathrm{o}} \mathbf{Y}_{\bmod }(\mathbf{p}) \approx \mathbf{A}_{\mathrm{o}} \mathbf{Y}_{\exp }
$$

Multiplying Eq. (17) with $\mathbf{A}_{\text {o }}$ gives

$$
\mathbf{A}_{0} \overline{\mathbf{Y}}_{\text {mod }}=\mathbf{A}_{0}\left(\overline{\mathbf{Y}}_{\text {exp }}+\Delta \overline{\mathbf{Y}}\right)
$$

Combining Eqs. (18) and (19) gives

$$
\begin{aligned}
\mathbf{A}_{\mathrm{o}}\left(\mathbf{Y}_{\bmod }(\mathbf{p})-\overline{\mathbf{Y}}_{\text {mod }}\right) & =\mathbf{A}_{\mathrm{o}}\left(\mathbf{Y}_{\exp }-\left(\overline{\mathbf{Y}}_{\exp }+\Delta \overline{\mathbf{Y}}\right)\right) \\
\mathbf{A}_{\mathrm{o}} \Delta \mathbf{Y}_{\text {mod }} & =\mathbf{A}_{\mathrm{o}}\left(\Delta \mathbf{Y}_{\exp }-\Delta \overline{\mathbf{Y}}\right)
\end{aligned}
$$

The error of $\mathbf{Y}_{\text {mod }}(\mathbf{p})$ can be related to the error of parameters with the help of Jacobian $\mathbf{J}_{\mathrm{o}}=\mathbf{J}\left(\mathbf{p}_{\mathrm{o}}\right)$ calculated at $\mathbf{p}_{\mathrm{o}}$

$$
\Delta \mathbf{Y}_{\text {mod }} \approx \mathbf{J}_{\mathrm{o}} \times \Delta \mathbf{p}
$$

where $\Delta \mathbf{p}=\mathbf{p}-\mathbf{p}_{\mathrm{o}}$ is the deviation of parameter set $\mathbf{p}$ from the optimal set.

Substituting Eq. (22) into Eq. (21) and solving it for $\Delta \mathbf{p}$ gives

$$
\Delta \mathbf{p} \approx\left(\mathbf{A}_{\mathrm{o}} \mathbf{J}_{\mathrm{o}}\right)^{-1} \mathbf{A}_{\mathrm{o}}\left(\Delta \mathbf{Y}_{\exp }-\Delta \overline{\mathbf{Y}}\right)
$$

Introducing the notation $\mathbf{B}_{\mathrm{o}}=\left(\mathbf{A}_{\mathrm{o}} \mathbf{J}_{\mathrm{o}}\right)^{-1} \mathbf{A}_{\mathrm{o}}$, the covariance matrix of the parameters $\left(\Sigma_{\mathbf{p}}\right)$ can be given in a compact form

$$
\begin{aligned}
\Sigma_{\mathbf{p}} & \approx \overline{\Delta \mathbf{p} \Delta \mathbf{p}^{\mathrm{T}}}=\mathbf{B}_{\mathrm{o}}\left(\overline{\Delta \mathbf{Y}_{\exp } \Delta \mathbf{Y}_{\exp }^{\mathrm{T}}}+\Delta \overline{\mathbf{Y}} \Delta \overline{\mathbf{Y}}^{\mathrm{T}}\right) \mathbf{B}_{\mathrm{o}}^{\mathrm{T}} \\
& =\mathbf{B}_{\mathrm{o}}\left(\boldsymbol{\Sigma}_{\mathbf{Y}}+\boldsymbol{\Sigma}_{\Delta}\right) \mathbf{B}_{\mathrm{o}}^{\mathrm{T}}
\end{aligned}
$$

Here, it is assumed that $\Delta \mathbf{Y}_{\exp }$ and $\Delta \overline{\mathbf{Y}}$ are uncorrelated.

The matrix $\boldsymbol{\Sigma}_{\mathbf{Y}}$ is the covariance matrix of vector $\mathbf{Y}_{\text {exp }}$. The matrix $\boldsymbol{\Sigma}_{\Delta}$ is related to the systematic deviations between the expectation results of the model and the experimental results. The expectation value $\overline{\mathbf{Y}}_{\text {exp }}$ and the covariance matrix $\boldsymbol{\Sigma}_{\mathbf{Y}}$ of the measured data points can be estimated by repeating the same measurement several times. However, doing measurements exactly at the same conditions is not possible in most cases; thus $\overline{\mathbf{Y}}_{\text {exp }}$ can be estimated by averaging the measured values belonging to similar conditions. If the measurement points are not dense enough, then the best guess for $\overline{\mathbf{Y}}_{\text {exp }}$ is the single measured value $\mathbf{Y}_{\exp }$, which also has a random scatter. In this case, the matrix $\boldsymbol{\Sigma}_{\Delta}$ can be estimated with $\boldsymbol{\Sigma}_{\Delta} \approx \Delta \mathbf{Y} \Delta \mathbf{Y}^{T}$, where $\Delta \mathbf{Y} \approx \overline{\mathbf{Y}}_{\text {mod }}-\mathbf{Y}_{\text {exp }}$. The matrix $\boldsymbol{\Sigma}_{\Delta}$ gives an upper 
estimate for the systematic deviations as it also includes the stochastic scatter of the experimental data.

Expanding the matrix $\mathbf{B}_{\mathrm{o}}$ in Eq. (24) yields

$$
\begin{aligned}
\boldsymbol{\Sigma}_{\mathbf{p}}= & {\left[\left(\mathbf{J}_{\mathrm{o}}^{\mathrm{T}} \mathbf{W} \boldsymbol{\Sigma}_{\mathbf{Y}}^{-1} \mathbf{J}_{\mathrm{o}}\right)^{-1} \mathbf{J}_{\mathrm{o}}^{\mathrm{T}} \mathbf{W} \boldsymbol{\Sigma}_{\mathbf{Y}}^{-1}\right]\left(\boldsymbol{\Sigma}_{\mathbf{Y}}+\boldsymbol{\Sigma}_{\boldsymbol{\Delta}}\right) } \\
& \times\left[\left(\mathbf{J}_{\mathrm{o}}^{\mathrm{T}} \mathbf{W} \boldsymbol{\Sigma}_{\mathbf{Y}}^{-1} \mathbf{J}_{\mathrm{o}}\right)^{-1} \mathbf{J}_{\mathrm{o}}^{\mathrm{T}} \mathbf{W} \boldsymbol{\Sigma}_{\mathbf{Y}}^{-1}\right]^{\mathrm{T}}
\end{aligned}
$$

The diagonal elements of the covariance matrix $\boldsymbol{\Sigma}_{\mathbf{p}}$ of the fitted parameters calculated by Eq. (25) are upper estimates for the variance of the parameters $\sigma^{2}\left(p_{i}\right)$. It takes into account the systematic discrepancies between the model and the measurement and also the scatter of experimental data. Equation (25) is a general equation for the determination of the covariance matrix of the parameters. The off-diagonal elements are covariances $\operatorname{cov}\left(p_{i}, p_{j}\right)=r_{p_{i}, p_{j}} \sigma_{p_{i}} \sigma_{p_{j}}$; therefore, the correlation coefficients $r_{p_{i}, p_{j}}$ can be calculated from the off-diagonal element and the standard deviations:

$$
r_{p_{i}, p_{j}}=\frac{\left(\boldsymbol{\Sigma}_{\mathbf{p}}\right)_{i, j}}{\sigma_{p_{i}} \sigma_{p_{j}}}
$$

Sheen and Wang [24] recently suggested a model optimization procedure based on the method of uncertainty minimization by polynomial chaos expansions. Their definition for the objective function and the method of calculation of the covariance matrix (see Eqs. (5) and (7) in [24]) uses similar but less general equations than those we derived here. For example, the handling of the weighting of the experimental data is more refined in the above equations. Another reason for the difference is that Sheen and Wang do not directly take into account the systematic deviation between the simulated and experimental values. Instead, they filter out those measurements (using Eq. (8) in [24]) that might induce large systematic error.

\section{Temperature Dependence of the Uncertainty Parameter $f$ and the Correlation of the Optimized Rate Coefficients}

In the fitting procedure, the parameters to be optimized are the Arrhenius parameters and possibly other parameters used at the simulation of gas kinetic systems, such as thermodynamic data, third-body efficiencies, and parameters of pressure dependence. However, the collections of evaluated data do not contain information about the uncertainty of the Arrhenius parameters, but characterize the uncertainty of the rate coefficients using uncertainty parameter $f$ (see Eq. (1)), which can be transformed to the standard deviation of the rate coefficient (see Eq. (2)). The chemical kinetics data collections have never dealt with the correlations between the values of the rate coefficients. Our final result for the uncertainty of the rate parameters, as deduced from the set of experimental data processed, is summarized in matrix $\boldsymbol{\Sigma}_{\mathbf{p}}$ (see Eq. (25)). Below, equations are derived to make comparable the content of matrix $\boldsymbol{\Sigma}_{\mathbf{p}}$ to the traditional uncertainty measures of chemical kinetics.

The linearized Arrhenius equation (3) has the following simpler form:

$$
\kappa_{i}(T)=\alpha_{i}+n_{i} \ln T-\varepsilon_{i} T^{-1}=\mathbf{p}_{i}^{\mathrm{T}} \boldsymbol{\Theta}=\boldsymbol{\Theta}^{\mathrm{T}} \mathbf{p}_{i}
$$

where $\kappa_{i}(T)=\ln \left\{k_{i}(T)\right\}, \quad \mathbf{p}_{i}:=\left(\alpha_{i}, n_{i}, \varepsilon_{i}\right)^{\mathrm{T}}, \quad$ and $\boldsymbol{\Theta}:=\left(1, \ln \{T\},-T^{-1}\right)^{\mathrm{T}}$.

Covariances $\operatorname{cov}\left(\kappa_{i}, \kappa_{j}\right)$ at temperature $T$ can be calculated in the following way:

$$
\begin{aligned}
\operatorname{cov}\left(\kappa_{i}(T), \kappa_{j}(T)\right) & \left.=\overline{\left(\kappa_{i}(T)-\bar{\kappa}_{i}(T)\right)\left(\kappa_{j}(T)-\bar{\kappa}_{j}(T)\right.}\right) \\
& =\boldsymbol{\Theta}^{T} \overline{\left(\mathbf{p}_{i}-\overline{\mathbf{p}}_{i}\right)\left(\mathbf{p}_{j}-\overline{\mathbf{p}}_{j}\right)^{T}} \boldsymbol{\Theta} \\
& =\boldsymbol{\Theta}^{T} \boldsymbol{\Sigma}_{\mathbf{p}_{i}, \mathbf{p}_{j}} \boldsymbol{\Theta}
\end{aligned}
$$

Here $\boldsymbol{\Sigma}_{\mathbf{p}_{i}, \mathbf{p}_{j}}$ denotes a block of matrix $\boldsymbol{\Sigma}_{\mathbf{p}}$ that contains the covariances of the Arrhenius parameters of reactions $i$ and $j$. Equation (28) provides the variance $\sigma_{\kappa_{i}}^{2}(T)$ if $i=j$. This variance can be transformed to the uncertainty parameter $f$ using Eq. (2). Thus, the $f(T)$ function obtained has a statistical background and can be deduced from experimental data in a transparent way.

The correlation of the logarithm of two rate coefficients $\left(r_{\kappa_{i}, \kappa_{j}}(T)\right)$ can be calculated by dividing their covariance with the product of their standard deviations at temperature $T$ :

$$
r_{\kappa_{i}, \kappa_{j}}(T)=\frac{\operatorname{cov}\left(\kappa_{i}(T), \kappa_{j}(T)\right)}{\sigma_{\kappa_{i}}(T) \sigma_{\kappa_{j}}(T)}
$$

\section{Encoding the Procedure}

The PrIMe database [38] contains XML data files that define kinetic experiments. Also, a utility program is provided with the database that allows encoding PrIMe data files from own measured or literature data. Our parameter optimization calculations were carried out using code Optima, which is a homemade MATLAB [39] code. The graphical user interface of Optima assists the selection of the parameters to be optimized, the PrIMe data files to be taken into account, and the control parameters. The ignition times were calculated with program Senkin [40], called from the Optima code. The 
Table I Evaluated and Optimized Rate Parameters for Reaction $\mathrm{H}+\mathrm{O}_{2}=\mathrm{OH}+\mathrm{O}(\mathrm{R} 1)$

\begin{tabular}{lccccr}
\hline Reference & $A\left(\mathrm{~cm}^{3} \mathrm{~mol}^{-1} \mathrm{~s}^{-1}\right)$ & $n$ & $E / R(\mathrm{~K})$ & $f$ & $T$ Range $(\mathrm{K})$ \\
\hline Baulch et al. [3] & $2.07 \times 10^{14}$ & -0.097 & 7560 & 0.1 at $800 \mathrm{~K}$, & $800-3500$ \\
& $3.55 \times 10^{15}$ & -0.41 & 8359 & 0.2 at 3500 K & - \\
Li et al. [41] & $1.91 \times 10^{14}$ & 0 & 8278 & - & - \\
Ó Conaire et al. [42] & $2.06 \times 10^{14}$ & -0.097 & 7564 & - & $800-3500$ \\
Konnov [43] & $1.04 \times 10^{14}$ & & 7705 & & $1100-3370$ \\
Hong et al. [44] & $3.003 \times 10^{10}$ & 0.965 & 6158 & 0.025 at $1000 \mathrm{~K}$, & $950-3550$ \\
This work & & & & 0.022 at $1500 \mathrm{~K}$, & 0.029 at 2000 K \\
& & & & &
\end{tabular}

process of optimization can be monitored using several diagnostic screens. In the end, the program creates one figure for each data set that shows the agreement between the measured and the calculated values. Also, the temperature dependence of the optimized rate coefficients and their uncertainty limits are displayed in Arrhenius plots.

\section{APPLICATION OF THE METHOD FOR TWO IMPORTANT REACTIONS OF THE HYDROGEN/OXYGEN SYSTEM}

The oxidation of hydrogen is one of the most important combustion processes. Hydrogen is one of the possible carbon-free fuels, an alternative to fossil fuels. Combustion of hydrogen is used in jet propulsion. The hydrogen combustion mechanism is the core of all wet $\mathrm{CO}$ and high-temperature hydrocarbon combustion mechanisms. New and updated hydrogen combustion mechanisms are still being published, such as the mechanisms of Li et al. [41], Ó Conaire et al. [42], Konnov [43], and Hong et al. [44]. These mechanisms describe the indirect measurements with similar accuracy, but different Arrhenius parameters are assigned to the important reaction steps. This shows that the accurate description of the combustion of hydrogen is still an open issue.

In all hydrogen combustion and in many hydrocarbon oxidation systems reactions (R1): $\mathrm{H}+\mathrm{O}_{2}=\mathrm{OH}$ $+\mathrm{O}$ and (R2): $\mathrm{H}+\mathrm{O}_{2}+\mathrm{M}=\mathrm{HO}_{2}+\mathrm{M}$ (low-pressure limit) are among the most important reactions. In accordance with their high importance, these elementary reactions have been widely studied. The rate parameters used by several authors are listed in Tables I and II. These rate coefficients are still not known with sufficient accuracy, and owing to the high sensitivity of the model results to the rate parameters of these reactions, small errors in their rate coefficients are amplified and cause high deviations in the simulation results. One of the aims of this article is to provide newly estimated values of the rate parameters of these reactions on the basis of a large number of measurement data.

Table II Evaluated Rate Parameters for Low-Pressure Limit Reaction $\mathrm{H}+\mathrm{O}_{2}+\mathrm{M}=\mathrm{HO}_{2}+\mathrm{M}$ (R2)

\begin{tabular}{|c|c|c|c|c|c|c|}
\hline Reference & Bath Gas & $A\left(\mathrm{~cm}^{6} \mathrm{~mol}^{-2} \mathrm{~s}^{-1}\right)$ & $n$ & $E / R(\mathrm{~K})$ & $f$ & $T$ Range (K) \\
\hline Baulch et al. [3] & $\mathrm{N}_{2}$ & $2.65 \times 10^{19}$ & -1.3 & 0 & $\begin{array}{l}0.1 \text { at } 298 \mathrm{~K} \\
0.2 \text { at } 2000 \mathrm{~K}\end{array}$ & 298-2000 \\
\hline Baulch et al. [3] & Ar & $6.9 \times 10^{18}$ & -1.2 & 0 & $\begin{array}{l}0.1 \text { at } 298 \mathrm{~K} \\
0.2 \text { at } 2000 \mathrm{~K}\end{array}$ & 298-2000 \\
\hline Li et al. [41] & $\mathrm{N}_{2}$ & $6.37 \times 10^{20}$ & -1.72 & 261.8 & - & - \\
\hline Li et al. [41] & $\mathrm{Ar}$ & $9.04 \times 10^{19}$ & -1.50 & 246.7 & - & - \\
\hline Ó Conaire et al. [42] & $\mathrm{N}_{2}$ & $3.482 \times 10^{16}$ & -0.41 & -561.5 & - & - \\
\hline Konnov [43] & $\mathrm{N}_{2}$ & $5.70 \times 10^{19}$ & -1.4 & 0 & 0.079 & $300-2000$ \\
\hline Konnov [43] & $\mathrm{Ar}$ & $7.43 \times 10^{18}$ & -1.2 & 0 & 0.079 & $300-2000$ \\
\hline Hong et al. [44] & $\mathrm{N}_{2}$ & $2.65 \times 10^{19}$ & -1.3 & 0 & - & - \\
\hline Hong et al. [44] & $\mathrm{Ar}$ & $6.81 \times 10^{18}$ & -1.2 & 0 & - & - \\
\hline This work & $\mathrm{N}_{2}$ & $7.856 \times 10^{18}$ & -1.100 & 0 & $\begin{array}{c}0.032 \text { at } 800 \mathrm{~K} \\
0.018 \text { at } 1000 \mathrm{~K} \\
0.045 \text { at } 1500 \mathrm{~K}\end{array}$ & $300-1850$ \\
\hline
\end{tabular}


Table III Ignition Time Measurements of Hydrogent-Oxygen Mixtures

\begin{tabular}{llccccc}
\hline No. & \multicolumn{1}{c}{ Reference } & Bath Gas & Number of Data Points & $1 \sigma(\%)$ & Initial $T$ Range (K) & Ignition $T$ Range (K) \\
\hline I1 & Petersen et al. [53] & $\mathrm{Ar}$ & 8 & 35 & $1189-1300$ & $1343-1391$ \\
I2 & Petersen et al. [54] & $\mathrm{Ar}$ & 2 & 18 & $1361-1366$ & $1363-1368$ \\
I3 & Petersen et al. [53] & $\mathrm{Ar}$ & 3 & 10 & $1279-1344$ & $1291-1357$ \\
I4 & Skinner and Ringrose [55] & $\mathrm{Ar}$ & 7 & 18 & $965-1075$ & $1430-1501$ \\
I5 & Slack [56] & $\mathrm{N}_{2}$ & 10 & 17 & $984-1045$ & $1804-1815$ \\
I6 & Bhaskaran et al. [57] & $\mathrm{N}_{2}$ & 4 & 6 & $1038-1081$ & $1845-1858$ \\
I7 & Wang et al. [58] & $\mathrm{N}_{2}$ & 6 & 15 & $1134-1272$ & $1650-1675$ \\
I8 & Wang et al. [58] & $\mathrm{N}_{2}$ & 10 & 27 & $955-1160$ & $1635-1648$ \\
I9 & Wang et al. [58] & $\mathrm{N}_{2}$ & 18 & 25 & $1080-1239$ & $1661-1703$ \\
I10 & Wang et al. [58] & $\mathrm{N}_{2}$ & 9 & 10 & $1152-1331$ & $1572-1636$ \\
I11 & Wang et al. [58] & $\mathrm{N}_{2}$ & 2 & 16 & $1244-1252$ & $1776-1789$ \\
\hline
\end{tabular}

\section{Selection of the Indirect and Direct Experiments}

The articles of Ó Conaire et al. [42] and Konnov [43] suggested updated hydrogen combustion mechanisms, discussed the information about the rate parameters of the most important reaction steps, and presented a large number of indirect measurements that were used for the "validation" of the mechanism. Some of these experimental data have already been present in the PrIMe database [38]. All indirect experiments discussed in the articles of Ó Conaire et al. [42] and Konnov [43] were encoded in PrIMe format. A utility program was written [45] that carries out the simulations using either the Chemkin-II [46] or the Cantera [47] simulation codes. During the simulations, the hydrogen submechanism of the National University of Ireland Galway (NUIG) natural gas mechanism (NGM) III $[48,49]$ was used. Local sensitivity analysis was performed to determine the most influential rate coefficients at each experimental condition. Experimental data were looked for where the simulation result corresponding to an experimentally measured quantity (e.g., ignition delay time or laminar flame velocity) is highly sensitive to the rate coefficient of the two reactions above, and the sensitivity coefficients belonging to the other rate coefficients are much smaller. All of these data happened to belong to ignition delay time experiments. In the case of the laminar flame velocity measurements and flow reactor experiments, the rate coefficients of several reactions (and not only these two) always had comparably high sensitivity. In some cases, only a part of the experimental data points was used in a data series, because at different conditions, other rate coefficients also had a large influence. Table III contains the ignition experiments that were used in this study. In all, 79 ignition delay time data were used from 11 measurement series.

Hong et al. recently studied [50] the combustion of $\mathrm{H}_{2} / \mathrm{O}_{2}$ mixtures, highly diluted with argon, in shock
Table IV Data of the $\mathrm{H}_{2} \mathrm{O}$ Concentration Profile Measurements by Hong et al. [44] in All Cases of Argon Used as Bath Gas

\begin{tabular}{lcccc}
\hline $\begin{array}{l}\text { Experimental } \\
\text { Series No. }\end{array}$ & $\begin{array}{c}\text { Number of } \\
\text { Data Points }\end{array}$ & $T(\mathrm{~K})$ & $p(\mathrm{~atm})$ & $1 \sigma(\mathrm{ppm})$ \\
\hline 1 & 7000 & 1100 & 1.95 & 15 \\
2 & 4000 & 1197 & 1.84 & 17 \\
3 & 3000 & 1256 & 2.01 & 17 \\
4 & 3000 & 1317 & 1.91 & 19 \\
5 & 2000 & 1448 & 1.85 & 25 \\
6 & 1500 & 1472 & 1.83 & 23 \\
\hline
\end{tabular}

tubes. They measured the $\mathrm{H}_{2} \mathrm{O}$ concentration as a function of time using tunable diode laser light absorption near $2.5 \mu \mathrm{m}$. We received the raw experimental data from the Hanson group (see Table IV), which contained 20,500 data points belonging to $\mathrm{H}_{2} \mathrm{O}$ concentrationtime profiles measured at six conditions. The supplementary data belonging to the article of Hong et al. [50] contain their determined rate coefficient of reaction (R1) at the previously mentioned 6 and further 14 conditions as a function of pressure, temperature, and mixture composition. These data were also used in our calculations.

Selection of the direct measurements to be considered in our studies was based on the reviews of Ó Conaire et al. [42], Konnov [43], and Hong et al. $[44,50]$. For reaction (R1), nine series of direct measurements (745 rate coefficient values) were selected. The details are given in Table V. For reaction (R2), 10 series of direct measurements (258 rate coefficient values) were used (see Table VI). The results of these direct experiments were also encoded in PrIMe-type XML format. For each series of experiments, these data files contained the literature reference, the experimental details and the values of the measured rate coefficient as data points, and the corresponding temperature and pressure values. 
Table V Direct Measurement Data for Reaction $\mathrm{H}+$ $\mathrm{O}_{2}=\mathrm{OH}+\mathrm{O}(\mathrm{R} 1)$

\begin{tabular}{lccc}
\hline Reference & $\begin{array}{c}\text { Number of } \\
\text { Data Points }\end{array}$ & $\begin{array}{c}1 \sigma \\
(\%)\end{array}$ & $\begin{array}{c}T \text { Range } \\
(\mathrm{K})\end{array}$ \\
\hline Masten et al. [59] & 30 & 10 & $1449-3370$ \\
Masten et al. [59] & 14 & 26 & $1452-2152$ \\
Du and Hessler [60] & 11 & 10 & $2050-2946$ \\
Yang et al. [61] & 20 & 10 & $1849-3549$ \\
Ryu et al. [62] & 178 & 10 & $1052-2501$ \\
Hwang et al. [63] & 189 & 10 & $948-3097$ \\
Pirraglia et al. [51] & 159 & 21 & $962-1705$ \\
Shin and Michael [64] & 124 & 30 & $1103-2059$ \\
Hong et al. [50] & 20 & 7 & $1091-1527$ \\
\hline
\end{tabular}

Table VI Direct Measurement Data Used for Reaction $\mathrm{H}+\mathrm{O}_{2}+\mathrm{M}=\mathrm{HO}_{2}+\mathrm{M}(\mathrm{R} 2)$

\begin{tabular}{|c|c|c|c|c|}
\hline Reference & $\begin{array}{l}\text { Bath } \\
\text { Gas }\end{array}$ & $\begin{array}{c}\text { Number } \\
\text { of Data } \\
\text { Points }\end{array}$ & $\begin{array}{c}1 \sigma \\
(\%)\end{array}$ & $\begin{array}{c}T \text { Range } \\
(\mathrm{K})\end{array}$ \\
\hline Pirraglia et al. [51] & $\mathrm{Ar}$ & 66 & 30 & 746-1006 \\
\hline Ashman and Haynes [65] & $\mathrm{Ar}$ & 7 & 10 & $725-899$ \\
\hline Ashman and Haynes [65] & $\mathrm{N}_{2}$ & 10 & 10 & $750-899$ \\
\hline Mueller et al. [66] & $\mathrm{N}_{2}$ & 6 & 10 & $830-862$ \\
\hline Mueller et al. [66] & $\mathrm{Ar}$ & 4 & 10 & $819-826$ \\
\hline Getzinger and Schott [67] & $\mathrm{Ar}$ & 96 & 17 & 1164-1849 \\
\hline Getzinger and Blair [68] & $\mathrm{N}_{2}$ & 10 & 12 & $1306-1612$ \\
\hline Blair and Getzinger [69] & $\mathrm{Ar}$ & 26 & 55 & $1435-1650$ \\
\hline Michael et al. [70] & $\mathrm{N}_{2}$ & 14 & 14 & $298-707$ \\
\hline Michael et al. [70] & $\mathrm{Ar}$ & 19 & 13 & $294-706$ \\
\hline
\end{tabular}

In all direct measurements series but one, the rate coefficient for either reaction (R1) or (R2) was determined at various temperatures and pressures. In the measurements of Pirraglia et al. [51] (listed in Table VI), the determined "apparent" pseudo-firstorder rate coefficient of $\mathrm{H}$-atom decay depended mainly on $k_{2}$ but also on the value of $k_{1}$. Pirraglia et al. derived $k_{2}$ values from their measurements based on an independently determined $k_{1}$ value. At the evaluation of the objective function, we used their expression for the calculation of the apparent rate coefficient using our Arrhenius parameters for both reactions (R1) and (R2). Our analysis was independent of the rate parameters of (R1) that they used in their original publication, and their data were used for the simultaneous determination of the Arrhenius parameters of both reactions.

For reaction (R2), the third-body efficiencies were identical to those used in the basic mechanism $[48,49]$. The only exception is the third-body efficiency for argon, which was one of the parameters to be optimized.

The objective function in Eq. (6) assumes the knowledge of the standard deviation of the experimental data.
This standard deviation includes both the systematic error and the random scatter. The random scatter of the data was estimated by the root-mean-square deviation of the data points from their moving average on $\ln k$ $(1 / T)$ and $\ln \tau(1 / T)$ Arrhenius-type plots. This random scatter was typically a few percent for about half of the direct measurements and above $10 \%$ for other direct measurements and also for most of the ignition delay times. The total (systematic and random) standard deviation was assumed to be at least $10 \%$ for all direct measurements, except for the data of Hong et al. [50]; as in this case, the authors estimated $7 \%$ on the basis of a detailed error analysis. The assumed $1 \sigma$ values of the measurements are given in Tables III, V, and VI, respectively. The standard deviation of the $\mathrm{H}_{2} \mathrm{O}$ profiles of Hong et al. [50] was estimated to be $15-25$ ppm by applying a similar procedure on water concentration vs. time plots (see Table IV).

\section{Determination of the Initial Uncertainty Domain of the Parameters}

For reaction (R1): $\mathrm{H}+\mathrm{O}_{2}=\mathrm{OH}+\mathrm{O}$, Baulch et al. [3] defined the uncertainty parameter as " 0.1 at $800 \mathrm{~K}$ rising to 0.2 at $3500 \mathrm{~K}$," whereas Konnov [43] assumed temperature-independent $f=0.176$. It is not possible to find an exact domain of uncertainty of the Arrhenius parameters on the basis of this information; therefore, a better defined $f(T)$ function had to be found. All rate parameters related to this elementary reaction were collected from the NIST Chemical Kinetics Database [52] and the latest evaluation of Baulch et al. [3]. Only the primary information sources were considered (experimental determination of the rate coefficient and highlevel theoretical calculations), whereas the evaluations and rate parameters used in previous modeling studies were not used. The primary information sources were analyzed one by one, and the presumably outdated results were also neglected. For all the remaining data (about 90 sets of rate parameters), the rate coefficients as a function of temperature were charted on an Arrhenius plot (see Fig. 1). It is clear that the experimentally determined rate coefficients cover a band. The middle line of the band coincides well with the Baulch evaluation [3], which was considered as $k^{0}(T)$. Also, it is possible to draw limiting $k^{\min }(T)$ and $k^{\max }(T)$ functions, positioned symmetrically below and above $k^{0}(T)$. Points $f(T)$ were defined at every $100 \mathrm{~K}$ (see Fig. 4 later in the paper). Using Eqs. (2), (4), and (5), the following elements of the covariance matrix of the Arrhenius parameters were determined: $\sigma_{\alpha}=4.622, \sigma_{n}$ $=0.581, \sigma_{\varepsilon}=675.7, r_{\alpha n}=-0.999852, r_{\alpha \varepsilon}=0.98788$, and $r_{n \varepsilon}=-0.99041$. Using these equations again, the self-consistent $f(T)$ function can be calculated 


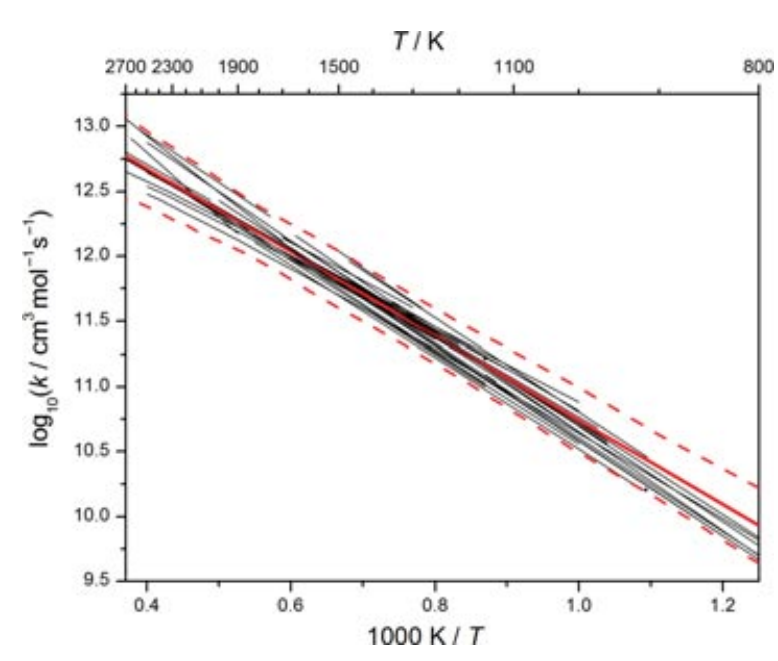

Figure 1 Arrhenius plot of all direct measurements of reaction (R1): $\mathrm{H}+\mathrm{O}_{2}=\mathrm{OH}+\mathrm{O}$ (thin lines). The mean value (thick red line) is identical to the Baulch et al. evaluation [3]. The upper and lower limits $\left(k^{\min }(T)\right.$ and $\left.k^{\max }(T)\right)$ are indicated by red dashed lines.

from the elements of the covariance matrix (see the corresponding solid line in Fig. 4 later in the paper). The uncertainty parameter $f$ changes between 0.21 and 0.33 in the temperature range of 800$2700 \mathrm{~K}$. This uncertainty will be used as the initial uncertainty domain in our parameter optimization calculations, and the optimal values of the parameters will be sought within this domain. This uncertainty is somewhat higher than the one defined by Baulch et al. [3] ( $f=0.1-0.2)$ and Konnov [43] $(f=0.176)$. Defining a wider range of uncertainty does not distort the final results (the optimized parameters); it only slightly increases the required computer time.

A similar procedure was used for reaction (R2): $\mathrm{H}+\mathrm{O}_{2}+\mathrm{M}=\mathrm{HO}_{2}+\mathrm{M}$ (low-pressure limit). Here, the problem is that the measured rate coefficient depends on the bath gas used. Most of the experimental data belonged to either nitrogen or argon bath gases. Application of other bath gases was rare. Two Arrhenius plots, one for nitrogen and one for argon, were created for the temperature dependence of the rate coefficient (see Figs. 2 and 3, respectively). Again, all primary data entries of the NIST Chemical Kinetics Database [52] and Baulch et al. [3] were used. In the next step, the few data belonging to obsolete measurements were deleted. Baulch et al. [3] recommend different Arrhenius parameters for nitrogen and argon bath gases. The ratio of the two rate coefficients depends on temperature and changes in the range of $0.48-0.53$. We selected the rate expression for nitrogen as a reference, and the rate coefficient for argon bulk gas was obtained by using a temperature-independent third-body effi-

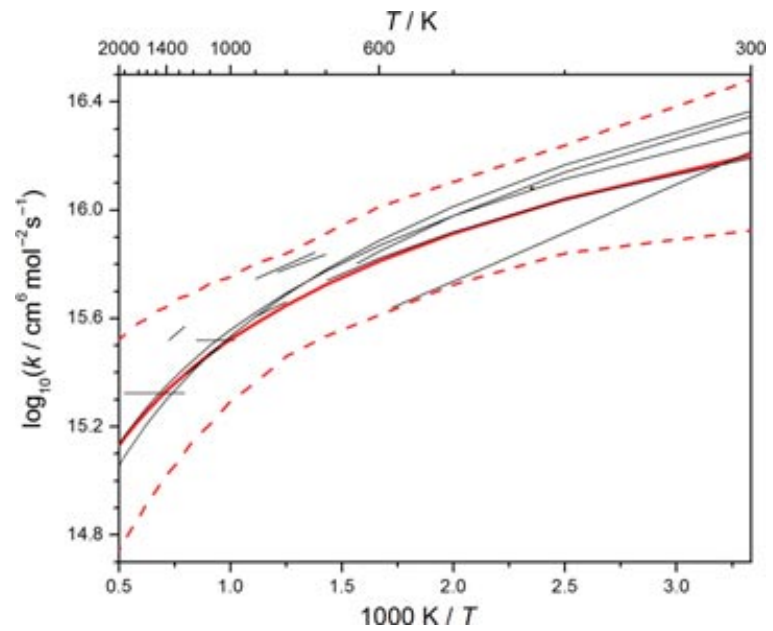

Figure 2 Arrhenius plot of all direct measurements for the low-pressure limit of reaction (R2): $\mathrm{H}+\mathrm{O}_{2}+\mathrm{N}_{2}=\mathrm{HO}_{2}+$ $\mathrm{N}_{2}$ (thin lines). The mean value (thick red line) is identical to the Baulch et al. evaluation [3]. The upper and lower limits $\left(k^{\min }(T)\right.$ and $\left.k^{\max }(T)\right)$ are indicated by red dashed lines.

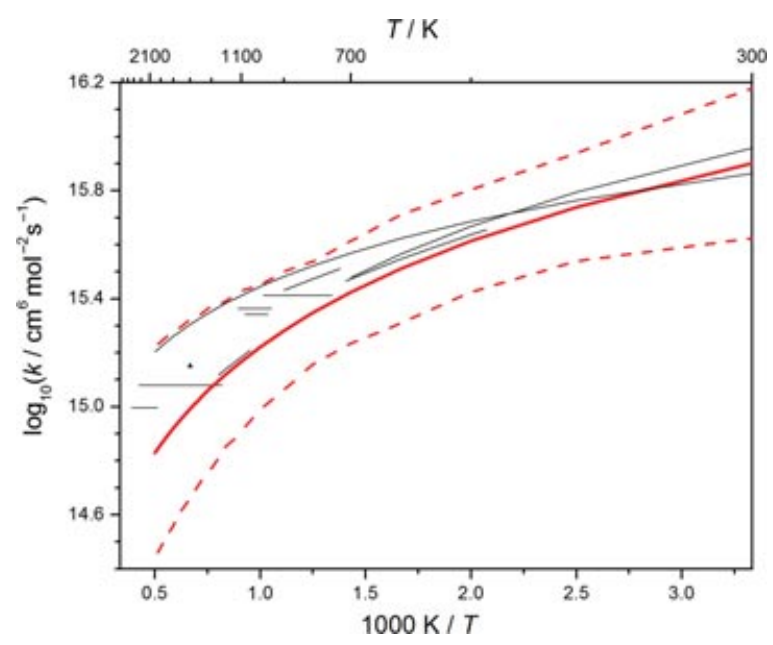

Figure 3 Arrhenius plot of all direct measurements for the low-pressure limit of reaction (R2): $\mathrm{H}+\mathrm{O}_{2}+\mathrm{Ar}=\mathrm{HO}_{2}+$ $\mathrm{Ar}$ (thin lines). The mean value (thick red line) is identical to the Baulch et al. evaluation [3]. The upper and lower limits $\left(k^{\min }(T)\right.$ and $\left.k^{\max }(T)\right)$ are indicated by red dashed lines.

ciency parameter of $m=0.50$ for argon. The thick red lines in Figs. 2 and 3 correspond to the Baulch et al. [3] recommendations for nitrogen by assuming third-body efficiency $m=1$ for nitrogen and $m=0.5$ for argon. Limiting $k^{\min }(T)$ and $k^{\max }(T)$ functions, positioned symmetrically below and above $k^{0}(T)$, were derived for the nitrogen measurements, and the same limits were applicable for argon. Points $f(T)$ were defined at every $100 \mathrm{~K}$ (see Fig. 4). The following elements of the covariance matrix of the Arrhenius parameters were determined: $\sigma_{\alpha}=1.787, \sigma_{n}=0.267, \sigma_{\varepsilon}=134.6, r_{\alpha n}$ $=-0.999864, r_{\alpha \varepsilon}=0.92117, r_{n \varepsilon}=-0.91462$. Also, 


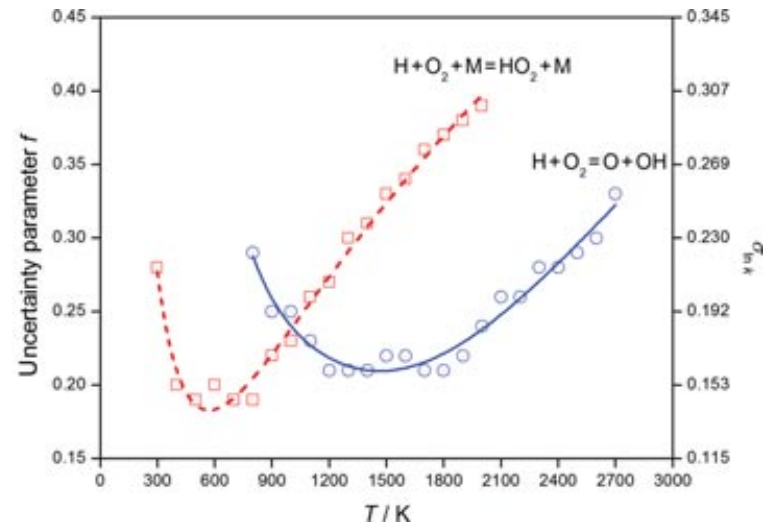

Figure 4 Uncertainty parameter $f$ values obtained from the $k^{\min }(T)$ and $k^{\max }(T)$ values at every $100 \mathrm{~K}$ temperature: Blue circles and red squares belong to reactions (R1) and (R2), respectively. The lines were calculated from the fitted covariance matrices: Solid blue line and red dashed line belong to reactions (R1) and (R2), respectively.

we considered the case when the Arrhenius expression includes parameters $A$ and $n$ only and $E$ is zero. Using the appropriate truncated forms of Eqs. (4) and (5), as derived by Nagy and Turányi [29], the initial domain of uncertainty of parameters $\alpha$ and $n$ was calculated and the following values were obtained: $\sigma_{\alpha}=1.4288$, $\sigma_{n}=0.2226$, and $r_{\alpha n}=-0.99514$.

These covariance matrices are common for bath gases nitrogen and argon. Figure 4 shows the selfconsistent $f(T)$ function calculated from the elements of the covariance matrix of $\alpha$ and $n$ (see the corresponding dashed line in Fig. 4). The uncertainty parameter $f$ changes between 0.18 and 0.40 in the range of temperature $298-2000 \mathrm{~K}$. This is again slightly more than the uncertainty defined by Baulch et al. [3] ( $f=0.1-0.2)$ and Konnov [43] ( $f=0.079)$.

No statistical information is available for the thirdbody efficiency of Ar relative to $\mathrm{N}_{2}$ in reaction (R2). In accordance with the Baulch et al. [3] recommendation, we assumed the value of $m$ having a normal distribution, with an expected value of 0.5 and with $s$ standard deviation of 0.1 .

\section{The Optimized Arrhenius Parameters and Their Uncertainty}

At the determination of the optimized rate parameters, the hydrogen submechanism of the NUIG NGM III $[48,49]$ was used. The optimization algorithm described in a previous section with 50 samples of parameter sets $(s=50)$ per cycle was applied to determine the transformed Arrhenius parameters and the third-body efficiency of argon. Note that the selection of the initial
Arrhenius parameters and the size of the initial uncertainty domain (provided that it is sufficiently large) are not critical for the final result of the optimization.

First, the twice three Arrhenius parameters of the two reactions and the third-body efficiency of argon were fitted. As Table II shows, Baulch et al. [3], Konnov [43], and Hong et al. [44] described the temperature dependence of reaction (R2) with Arrhenius parameters $A$ and $n$ only. In the second series of calculations, three Arrhenius parameters were fitted for reaction (R1) and two Arrhenius parameters ( $A$ and $n$ ) and the third-body efficiency of argon for reaction (R2). At the optimal parameter set, the value of the objective function was almost identical to the previous case; therefore, we concluded that the two-parameter Arrhenius expression describes the temperature dependence of the rate coefficient of reaction (R2) well.

In the calculations above, the direct measurements did not include those of Hong et al. [50] (see the last row of Table V), but the $\mathrm{H}_{2} \mathrm{O}$ profiles (six data series) measured by these authors [50] were considered as indirect measurement data (see Table IV). All calculations were repeated in such a way that the measurements of Hong et al. [50] were considered as direct measurements only (20 data points). The two calculations provided similar optimized rate parameters, but the former calculation (based on measured $\mathrm{H}_{2} \mathrm{O}$ profiles) indicated much smaller uncertainty of the rate parameters. We accepted the results obtained in the latter calculations. The reason for this is that the uncertainty in the measurements of Hong et al. [50] comes not only from the statistical error in the measured $\mathrm{H}_{2} \mathrm{O}$ profiles but also from other conditions of the experiment (e.g., determination of the temperature). Therefore, the error analysis published by Hong et al. [50] seems to be a better starting point for our calculation of the uncertainty domain of the rate parameters. Thus, all further results refer to the utilization of all direct measurements as given in Table $\mathrm{V}$, and the $\mathrm{H}_{2} \mathrm{O}$ profiles (Table IV) were disregarded in these optimization studies.

Tables I and II for reactions (R1) and (R2), respectively, show the optimized Arrhenius parameters, the uncertainty of rate coefficients, and the temperature range of validity as given in the evaluations of Baulch et al. [3], Li et al. [41], Ó Conaire et al. [42], Konnov [43], and Hong et al. [44]. The rows of these tables also provide the optimized parameters for these reactions. The temperature range indicated for the parameters optimized in this work corresponds to the temperature range of the direct and indirect measurements, which is about $950-3550 \mathrm{~K}$ for reaction (R1) and 300$1850 \mathrm{~K}$ for reaction (R1). The optimized third-body efficiency (Ar relative to $\mathrm{N}_{2}$ ) in reaction (R2) is $m=$ 0.494 . 
Table VII The Determined Covariances of the Rate Parameters

\begin{tabular}{|c|c|c|c|c|c|c|}
\hline & $\ln A_{1}$ & $n_{1}$ & $E_{1} / R$ & $\ln A_{2}$ & $n_{2}$ & $m$ (Ar) \\
\hline $\ln A_{1}$ & $1.0609 \times 10^{0}$ & $-1.2149 \times 10^{-1}$ & $2.3661 \times 10^{2}$ & $-4.4080 \times 10^{-1}$ & $6.3586 \times 10^{-2}$ & $-3.0367 \times 10^{-3}$ \\
\hline$n_{1}$ & & $1.3924 \times 10^{-2}$ & $-2.6989 \times 10^{1}$ & $4.9745 \times 10^{-2}$ & $-7.1782 \times 10^{-3}$ & $3.5276 \times 10^{-4}$ \\
\hline$E_{1} I R$ & & & $5.3824 \times 10^{4}$ & $-1.0438 \times 10^{2}$ & $1.5020 \times 10^{1}$ & $-6.0886 \times 10^{-1}$ \\
\hline $\ln A_{2}$ & & & & $3.3293 \times 10^{-1}$ & $-4.7993 \times 10^{-2}$ & $7.4402 \times 10^{-4}$ \\
\hline$n_{2}$ & & & & & $6.9222 \times 10^{-3}$ & $-1.1576 \times 10^{-4}$ \\
\hline$m(\mathrm{Ar})$ & & & & & & $9.2352 \times 10^{-5}$ \\
\hline
\end{tabular}

Table VIII The Determined Correlations of the Rate Parameters

\begin{tabular}{|c|c|c|c|c|c|c|}
\hline & $\ln A_{1}$ & $n_{1}$ & $E_{1} / R$ & $\ln A_{2}$ & $n_{2}$ & $m$ (Ar) \\
\hline $\ln A_{1}$ & 1 & -0.99957 & 0.99015 & -0.74170 & 0.74199 & -0.30679 \\
\hline$n_{1}$ & & 1 & -0.98586 & 0.73062 & -0.73116 & 0.31108 \\
\hline$E_{1} / R$ & & & 1 & -0.77976 & 0.77814 & -0.27309 \\
\hline $\ln A_{2}$ & & & & 1 & -0.99973 & 0.13418 \\
\hline$n_{2}$ & & & & & 1 & -0.14478 \\
\hline$m(\mathrm{Ar})$ & & & & & & 1 \\
\hline
\end{tabular}

The determined standard deviations are $\sigma\left(\ln A_{1}\right)=$ 1.03, $\sigma\left(n_{1}\right)=0.118, \sigma\left(E_{1} / R\right)=232 \mathrm{~K}, \sigma\left(\ln A_{2}\right)=$ 0.577, $\sigma\left(n_{2}\right)=0.0832$, and $\sigma(m)=0.00961$. Tables VII and VIII give the covariance and correlation matrices, respectively, of all optimized parameters. The elements of the covariance and correlation matrices have to be defined with five significant figures to ensure the calculation of the $f(T)$ function and correlation $r_{\kappa_{i}, \kappa_{j}}(T)$ with an accuracy of two significant figures. There is a strong correlation between the Arrhenius parameters for each reaction. Also, the simulated ignition delay times and the results of the Pirraglia et al. [51] measurements depend on the rate parameters of both reactions; therefore, correlation was also found between all the investigated rate parameters of reactions (R1) and (R2). The covariance matrix of the fitted parameters allows the calculation of the covariance matrix of parameters $\ln k_{1}$ and $\ln k_{2}$ at any temperature. Using this temperature-dependent matrix, the uncertainty parameters $f$ and the correlation coefficients as a function of temperature can be calculated by using Eqs. (2) and (29).

Figure 5 shows the Arrhenius plots of the initial and optimized rate parameters and their uncertainty limits for reaction (R1). The optimized values coincide well with the Baulch et al. recommendation, but the uncertainty limits are much smaller. Figure 6 presents a similar Arrhenius plot for reaction (R2). Here, the temperature dependence of the optimized rate coefficient deviates more from that of the Baulch et al. recommendation, but the new value and its uncertainty limits are well within the uncertainty limits determined from the direct measurements.

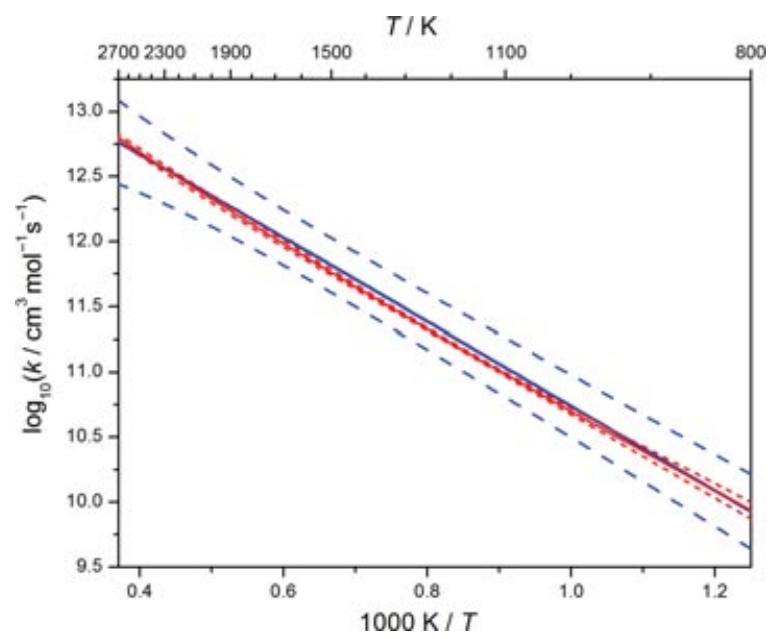

Figure 5 Arrhenius plots of the initial and optimized main values and uncertainty limits for reaction (R1): $\mathrm{H}+\mathrm{O}_{2}=$ $\mathrm{OH}+\mathrm{O}$. Thin solid blue line: initial value, recommended by Baulch et al. [3]; blue dashed lines: initial uncertainty limits; red line: optimized rate coefficient; red dashed lines: optimized uncertainty limits.

Figures 7 and 8 show uncertainty functions $f(T)$ for reactions (R1) and (R2), respectively. The uncertainties belonging to the optimized rate parameters are much lower than the uncertainties reported by Baulch et al. [3]. The low uncertainty comes from taking into account both the direct and indirect measurements.

Figure 9 shows the temperature dependence of the correlation coefficient between the logarithms of the optimized rate coefficients of reactions (R1) and (R2). By increasing the rate coefficients of reactions (R1) 


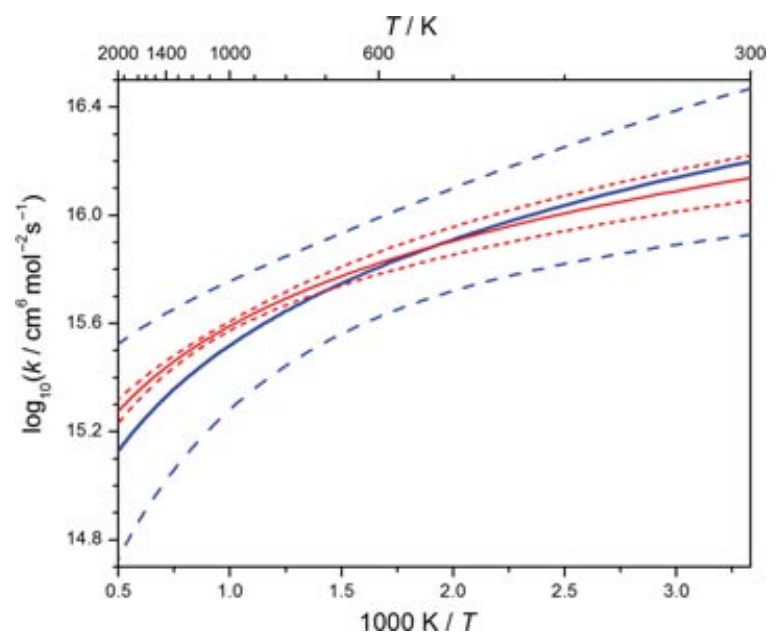

Figure 6 Arrhenius plots of the initial and optimized main values and uncertainty limits for reaction (R2): $\mathrm{H}+\mathrm{O}_{2}+$ $\mathrm{N}_{2}=\mathrm{HO}_{2}+\mathrm{N}_{2}$ (low-pressure limit). Thin solid blue line: initial value, recommended by Baulch et al. [3]); blue dashed lines: initial uncertainty limits; red line: optimized rate coefficient; red dashed lines: optimized uncertainty limits.

and (R2), the calculated ignition delay time decreases and increases, respectively. Therefore, the simultaneous increase of both rate coefficients may keep the ignition delay time constant. This is the reason for the high positive correlation between the logarithms of the two rate coefficients. The correlation is usually around 0.8 , whereas it is slightly smaller at 1050 $1150 \mathrm{~K}$. It is in accordance with that the uncertainty of the determined rate coefficients of both reactions is

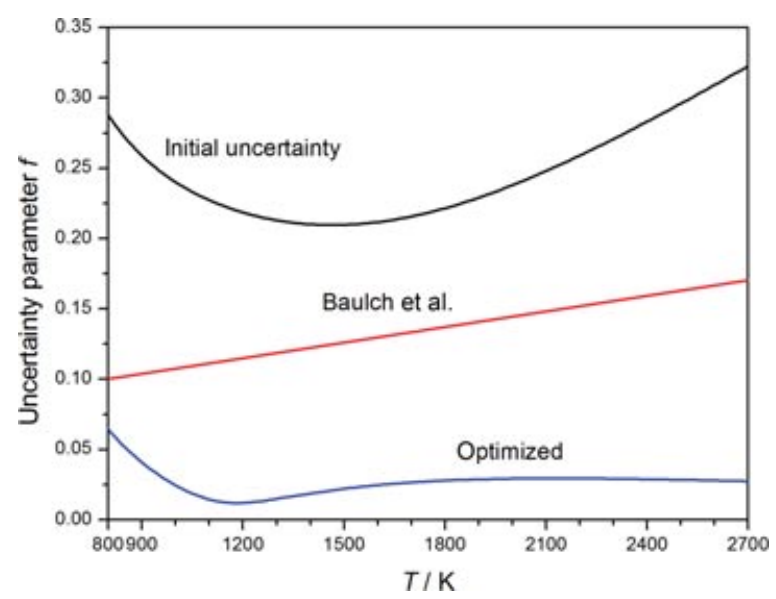

Figure 7 Uncertainty parameter $(f)$ as a function of temperature for reaction (R1): $\mathrm{H}+\mathrm{O}_{2}=\mathrm{OH}+\mathrm{O}$, according to the evaluation of Baulch et al. [3] (red line), and $f$ calculated from the covariance matrix of the Arrhenius parameters in two different ways: The "initial uncertainty" belongs to the $k^{\min }(T)$ and $k^{\max }(T)$ functions (black line), and the "optimized" belongs to the optimized rate parameters (blue line).

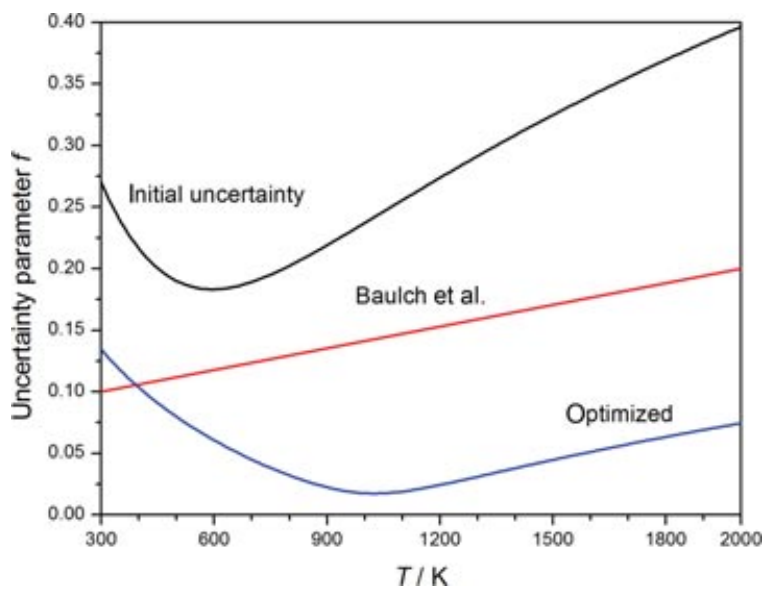

Figure 8 Uncertainty parameter $(f)$ as a function of temperature for reaction (R2): $\mathrm{H}+\mathrm{O}_{2}+\mathrm{N}_{2}=\mathrm{HO}_{2}+\mathrm{N}_{2}$ (low-pressure limit) according to the evaluation of Baulch et al. [3] (red line), and $f$ calculated from the covariance matrix of the Arrhenius parameters in two different ways: The "initial uncertainty" belongs to the $k^{\min }(T)$ and $k^{\max }(T)$ functions (black line), and the "optimized" belongs to the optimized rate parameters (blue line).

small in this region, which makes them less correlated (see the lower panel of Fig. 9).

All calculations were repeated using the very recent mechanism of Hong et al. [44]. In these calculations also the Arrhenius parameters of reactions (R1) and (R2), and third-body efficiency $m$ were optimized using the same set of experimental data. The determined Arrhenius parameters were slightly different, but the rate coefficients calculated at various temperatures were very similar. For example at $1000 \mathrm{~K}$, $k_{1}(\mathrm{NUIG})=5.00 \times 10^{10} \mathrm{~cm}^{3} \mathrm{~mol}^{-1} \mathrm{~s}^{-1}, k_{1}($ Hong $)=$

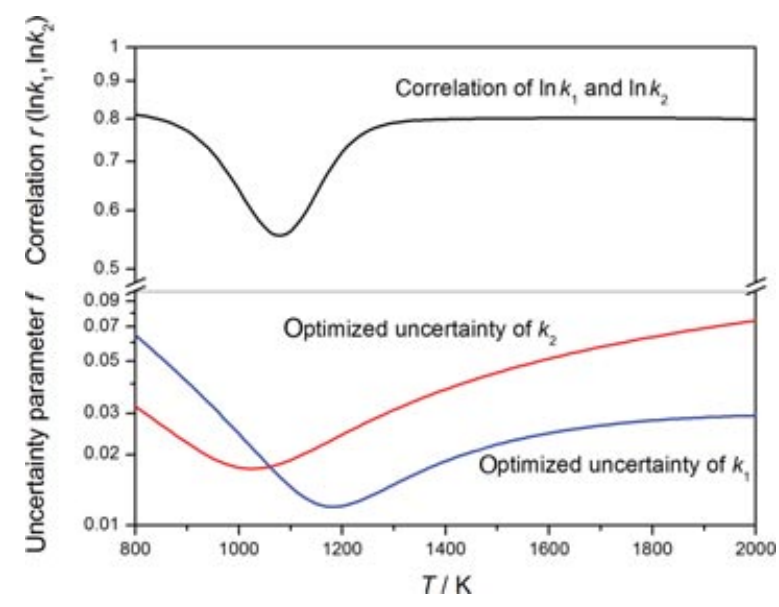

Figure 9 Correlation coefficient $(r)$ between the logarithm of the rate coefficients of reactions (R1) and (R2) as a function of temperature. The lower panel shows the simultaneous change of the uncertainties of the rate coefficients. 
$5.18 \times 10^{10} \mathrm{~cm}^{3} \mathrm{~mol}^{-1} \mathrm{~s}^{-1}(+3.5 \%) ;$ at $1500 \mathrm{~K}$, $k_{1}(\mathrm{NUIG})=5.76 \times 10^{11} \mathrm{~cm}^{3} \mathrm{~mol}^{-1} \mathrm{~s}^{-1}, k_{1}$ (Hong) $=$ $5.75 \times 10^{11} \mathrm{~cm}^{3} \mathrm{~mol}^{-1} \mathrm{~s}^{-1}(-0.2 \%)$; for nitrogen bath gas at $1000 \mathrm{~K}, k_{2}(\mathrm{NUIG})=3.94 \times 10^{15} \mathrm{~cm}^{6} \mathrm{~mol}^{-2} \mathrm{~s}^{-1}$, $k_{2}$ (Hong) $=3.96 \times 10^{15} \mathrm{~cm}^{6} \mathrm{~mol}^{-2} \mathrm{~s}^{-1}(+0.7 \%)$; at $1500 \mathrm{~K}, k_{2}(\mathrm{NUIG})=2.52 \times 10^{15} \mathrm{~cm}^{6} \mathrm{~mol}^{-2} \mathrm{~s}^{-1}$, $k_{2}$ (Hong) $=2.57 \times 10^{15} \mathrm{~cm}^{6} \mathrm{~mol}^{-2} \mathrm{~s}^{-1}(+1.8 \%)$.

The value of the objective function in Eq. (6) can be used as a single figure to characterize how well a mechanism reproduces the measurements. First, the objective function was evaluated using the original hydrogen submechanism of the NUIG NGM III $[48,49]$ and the Hong et al. hydrogen mechanism [44]. Without optimization, the NUIG mechanism described the experimental data better than the Hong et al. mechanism, since the objective function values were 189 and 371 , respectively. Thereafter, the reaction steps corresponding to reactions (R1) and (R2) were replaced with those of the recommendations of Baulch et al. [3]. In the case of (R2), the high-pressure-limit Arrhenius parameters in the NUIG mechanism were used also for the Hong et al. mechanism. This modification significantly increased the overall error for NUIG NGM III, but slightly decreased it for the Hong et al. mechanism (358 and 338, respectively). After optimizing the six rate parameters, both mechanisms performed significantly better and had almost the same error (106 and 109 , respectively). It is interesting to investigate how the mechanisms describe the direct and indirect measurements separately. The original NUIG NGM is in good accordance with the direct measurements; therefore, the optimization was not able to decrease the value of the objective function significantly (lowering from 40 to 33). The original Hong et al. mechanism predicted the direct measurements less accurately, but its error decreased significantly as a result of the optimization (from 100 to 33).

Figure 10 presents the correlations of the partial objective functions (see Eq. (6)) of the indirect experiments obtained with the NUIG [48,49] and the Hong et al. mechanisms [44]. When the original mechanisms are tested, these values show poor correlation (correlation coefficient $r_{E}=0.37$; see the black squares and the fitted black dotted line), indicating that these mechanisms were developed independently. The intercept and the slope of the fitted line are 15.2 and 0.70 , respectively, showing a systematic deviation. Inclusion of the Baulch et al. [3] recommended values for reactions (R1) and (R2) enhanced the correlation (slope $s=$ 0.87 , correlation coefficient $r_{E}=0.98$; red circles and red dashed line), but a large overall error remained. After the optimization, both mechanisms performed very well and all deviations from the experimental data became similar (slope $s=0.98$, correlation coefficient

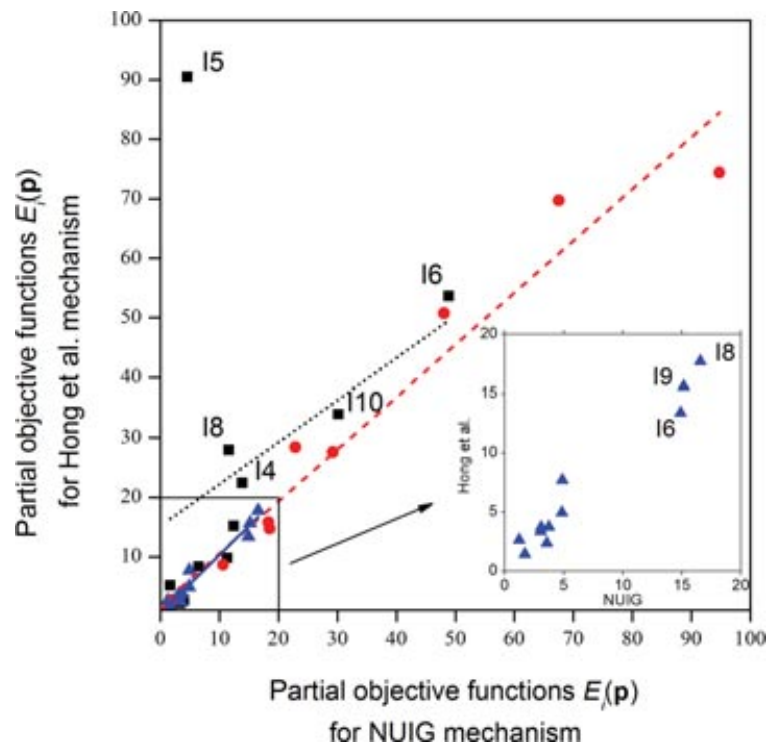

Figure 10 The symbols indicate the values of the partial objective function belonging to each series of the indirect experiments (listed in Table III), and the lines are the linear functions fitted to the corresponding points. When the original NUIG and Hong et al. mechanisms are tested, these values show poor correlation (black squares and black dotted line). Inclusion of the Baulch et al. [3] recommended values for reactions (R1) and (R2) enhanced the correlation (red circles and red dashed line), but a large overall error remained. After the optimization, deviations from the experimental data decreased and became similar for both mechanisms (blue triangles and solid blue line). The insert shows the values of the partial objective function for the optimized mechanism only. The labeling of the outlying points is in accordance with Table III.

$r_{E}=0.98$; blue triangles and blue solid line). This means that the other rate parameters used in these mechanisms do not have high influence on the simulation results at the conditions of the indirect experiments used. This is not surprising, as these experiments had been selected in such a way to be sensitive to the rate parameters of these two reactions only. The good correlation is an a posteriori justification of our procedure aiming at the determination of the rate parameters of these two reactions. Therefore, the optimized rate parameters can be considered as new recommended values for reactions (R1) and (R2). A possible continuation of this work is to take into account other bath gases and a more refined handling of multicomponent bath gases [71]. The optimized mechanisms, however, are not new optimized mechanisms since other hydrogen oxidation experiments have not been taken into account. Using all available measurements and optimizing all relevant rate parameters of the hydrogen combustion mechanism are needed to obtain fully optimized mechanisms. 


\section{CONCLUSIONS}

The determination of the rate parameters of elementary reactions in gas kinetics is primarily based on direct kinetic measurements. However, these values have a relatively high uncertainty, which causes high uncertainty in the simulation results of combustion models [21,22,32-36]. Repeated, direct measurements of important reactions, even made independently by several groups, did not decrease the uncertainty of the rate coefficients below a certain limit [4].

The uncertainty of the rate coefficients can be reduced further efficiently if indirect measurements are also taken into account. Pursuing this idea, a new methodology is devised that has several advantageous features. Arrhenius parameters $A, n$, and $E$ of selected reactions and possibly other critical rate parameters (like third-body coefficient, $m$ ) can be fitted to give a good reproduction of both direct and indirect measurements. This way, the information content of many experimental data of different types is utilized.

The method was used to get new recommended values with smaller uncertainty for the rate parameters of reactions (R1): $\mathrm{H}+\mathrm{O}_{2}=\mathrm{OH}+\mathrm{O}$ and (R2): $\mathrm{H}+\mathrm{O}_{2}$ $+\mathrm{M}=\mathrm{HO}_{2}+\mathrm{M}$ (low-pressure limit; $\mathrm{M}=\mathrm{N}_{2}$ or Ar). Application of the method resulted in the following rate parameters for the investigated reactions- $(\mathrm{R} 1)$ : $A_{1}=3.003 \times 10^{10} \mathrm{~cm}^{3} \mathrm{~mol}^{-1} \mathrm{~s}^{-1}, n_{1}=0.965, E_{1} / R$ $=6158 \mathrm{~K}(T=950-3550 \mathrm{~K})$ and $(\mathrm{R} 2): A_{2}=7.856 \times$ $10^{18} \mathrm{~cm}^{6} \mathrm{~mol}^{-2} \mathrm{~s}^{-1}, n_{2}=-1.100, E / R=0 \mathrm{~K}$ (lowpressure limit; $\left.\mathrm{M}=\mathrm{N}_{2}, T=300-1850 \mathrm{~K}\right)$. The optimized third-body efficiency of Ar relative to $\mathrm{N}_{2}$ is $m$ $=0.494$. The determined standard deviations are $\sigma(\ln$ $\left.A_{1}\right)=1.03, \sigma\left(n_{1}\right)=0.118, \sigma\left(E_{1} / R\right)=232 \mathrm{~K}, \sigma(\ln$ $\left.A_{2}\right)=0.577, \sigma\left(n_{2}\right)=0.0832$, and $\sigma(m)=0.00961$. The covariance matrix of all optimized rate parameters (see Table VII) provides a very detailed description of the joint uncertainty of these parameters.

This approach can be used for two types of problems: the utilization of the results of indirect measurements [72] and the optimization of whole mechanisms. Experimental data are frequently interpreted in such a way that the low uncertainty rate parameters are fixed at their literature value, and parameters having high uncertainty are fitted to the measured values even if the low uncertainty parameters have high sensitivity at the experimental conditions. The methodology described here suggests an alternative approach, when all parameters having high sensitivity are fitted to all experimental data, available from own measurements or from the literature. These data can be results of direct measurements (usually measured rate coefficients are reported) or of indirect measurements (such as timeto-ignition or laminar flame velocity). Our approach can also be used for the optimization of whole reaction mechanisms, provided that a large amount of experimental data are available.

This work was done within collaboration COST Action CM0901: Detailed Chemical Kinetic Models for Cleaner Combustion. The authors are grateful for helpful discussions with Prof. Michael J. Pilling, Drs. Judit Zádor and János Tóth, and Mr. László Varga. We are indebted to Dr. D. F. Davidson for providing us with the Stanford University raw $\mathrm{H}_{2} \mathrm{O}$ profile measurement data [50].

\section{BIBLIOGRAPHY}

1. Baulch, D. L.; Cobos, C. J.; Cox, R. A.; Esser, C.; Frank, P.; Just, T.; Kerr, J. A.; Pilling, M. J.; Troe, J.; Walker, R. W.; Warnatz, J. J Phys Chem Ref Data 1992, 21, 411.

2. Baulch, D. L.; Cobos, C. J.; Cox, R. A.; Frank, J. H.; Hayman, G.; Just, T. H.; Kerr, J. A.; Murrels, T.; Pilling, M. J.; Troe, J.; Walker, B. F.; Warnatz, J. Combust Flame 1994, 98, 59.

3. Baulch, D. L.; Bowman, C. T.; Cobos, C. J.; Cox, R. A.; Just, T.; Kerr, J. A.; Pilling, M. J.; Stocker, D.; Troe, J.; Tsang, W.; Walker, R. W.; Warnatz, J. J Phys Chem Ref Data 2005, 34, 757-1397.

4. Miller, J. A.; Pilling, M. J.; Troe, J. Proc Combust Inst 2005, 30, 43-88.

5. Miller, D.; Frenklach, M. Int J Chem Kinet 1983, 15, 677-696.

6. Frenklach, M. Combust Flame 1984, 58, 69-72.

7. Frenklach, M.; Wang, H.; Rabinowitz, M. J. Prog Energy Combust Sci 1992, 18, 47-73.

8. GRI-Mech 1.2, 1995. Available at http://diesel.me .berkeley.edu/ gri_mech/new21/version12/text12.html. Accessed 23 November 2011.

9. GRI-Mech 2.11, 1995. Available at http://diesel.me .berkeley.edu/ gri_mech/new21/version21/text21.html. Accessed 23 November 2011.

10. GRI-Mech 3.0, 1999. Available at http://www.me .berkeley.edu/gri_mech/. Accessed 23 November 2011.

11. Frenklach, M.; Packard, A.; Seiler, P.; Feeley, R. Int J Chem Kinet 2004, 36, 57-66.

12. Frenklach, M.; Packard, A.; Seiler, P. In American Control Conference, Anchorage, AK, May 2002; pp. 41354140.

13. Feeley, R.; Seiler, P.; Packard, A.; Frenklach, M. J Phys Chem A 2004, 108, 9573-9583.

14. Seiler, P.; Frenklach, M.; Packard, A.; Feeley, R. Optim Eng 2006, 7, 459-478.

15. Feeley, R.; Frenklach, M.; Onsum, M.; Russi, T.; Arkin, A.; Packard, A. J Phys Chem A 2006, 110, 6803-6813.

16. Russi, T.; Packard, A.; Feeley, R.; Frenklach, M. J Phys Chem A 2008, 112, 2579-2588.

17. Frenklach, M. Proc Combust Inst 2007, 31, 125-140. 
18. You, X. Q.; Russi, T.; Packard, A.; Frenklach, M. Proc Combust Inst 2011, 33, 509-516.

19. Qin, Z.; Lissianski, V.; Yang, H.; Gardiner, W.; Davis, S.; Wang, H. Proc Combust Inst 2000, 28, 1663-1669.

20. Davis, S. G.; Joshi, A. V.; Wang, H.; Egolfopoulos, F. N. Proc Combust Inst 2005, 30, 1283-1292.

21. Sheen, D. A.; You, X.; Wang, H.; Løvås, T. Proc Combust Inst 2009, 32, 535-542.

22. Sheen, D. A.; Wang, H. Combust Flame 2011, 158, 645656.

23. Davis, S. G.; Mhadeshwar, A. B.; Vlachos, D. G.; Wang, H. Int J Chem Kinet 2004, 36, 94-106.

24. Sheen, D. A.; Wang, H. Combust Flame 2011, 158, 2358-2374.

25. Ruscic, B.; Pinzon, R. E.; Morton, M. L.; von Laszevski, G.; Bittner, S. J.; Nijsure, S. G.; Amin, K. A.; Minkoff, M.; Wagner, A. F. J Phys Chem A 2004, 108, 9979.

26. Ruscic, B.; Wagner, A. F.; Harding, L. B.; Asher, R. L.; Feller, D.; Dixon, D. A.; Peterson, K. A.; Song, Y.; Qian, X.; Ng, C.; Liu, J.; Chen, W.; Schwenke, D. W. J Phys Chem A 2002, 106, 2727-2747.

27. Császár, A. G.; Furtenbach, T. Chem Eur J 2010, 16, 4826-4835.

28. Scire, J. J.; Dryer, F. L.; Yetter, R. A. Int J Chem Kinet 2001, 33, 784-802.

29. Nagy, T.; Turányi, T. Int J Chem Kinet 2011, 43, 359378.

30. Baulch, D. L. Personal communication, 1995.

31. Brown, M. J.; Smith, D. B.; Taylor, S. C. Combust Flame 1999, 117, 652-656.

32. Turányi, T.; Zalotai, L.; Dóbé, S.; Bérces, T. Phys Chem Chem Phys 2002, 4, 2568-2578.

33. Zsély, I. G.; Zádor, J.; Turányi, T. Int J Chem Kinet 2008, 40, 754-768.

34. Zsély, I. G.; Zádor, J.; Turányi, T. Proc Combust Inst 2005, 30/(1), 1273-1281.

35. Zádor, J.; Zsély, I. G.; Turányi, T.; Ratto, M.; Tarantola, S.; Saltelli, A. J Phys Chem A 2005, 109, 9795-9807.

36. Zádor, J.; Zsély, I. G.; Turányi, T. Reliab Eng Syst Saf 2006, 91, 1232-1240.

37. Hébrard, E.; Dobrijevic, M.; Pernot, P.; Carrasco, N.; Bergeat, A.; Hickson, K. M.; Canosa, A.; Picard, S. D. L.; Sims, I. R. J Phys Chem A 2009, 113, $11227-$ 11237.

38. PrIMe Database. Available at http://www.primekinetics .org/. Accessed 23 November 2011.

39. MATLAB version R2007a; The MathWorks Inc.: Natick, MA, 2007

40. Lutz, A. E.; Kee, R. J.; Miller, J. A. Senkin: A FORTRAN Program for Predicting Homogeneous Gas Phase Chemical Kinetics with Sensitivity Analysis, SAND878248; Sandia National Laboratories: Albuquerque, NM, 1988.

41. Li, J.; Zhao, Z.; Kazakov, A.; Dryer, F. L. Int J Chem Kinet 2004, 36, 566-576.

42. Ó Conaire, M.; Curran, H. J.; Simmie, J. M.; Pitz, W. J.; Westbrook, C. K. Int J Chem Kinet 2004, 36, $603-$ 622
43. Konnov, A. A. Combust Flame 2008, 152, 507-528.

44. Hong, Z.; Davidson, D. F.; Hanson, R. K. Combust Flame 2011, 158, 633-644.

45. Varga, T.; Zsély, I. G.; Turányi, T. In Proceedings of the European Combustion Meeting 2011, Cardiff, UK, June 2011.

46. Kee, R. J.; Rupley, F. M.; Miller, J. A. CHEMKIN-II: A FORTRAN Chemical Kinetics Package for the Analysis of Gas-Phase Chemical Kinetics, SAND79-8009B; Sandia National Laboratories: Albuquerque, NM, 1989

47. Cantera: An open-source, object-oriented software suite for combustion. Available at http://sourceforge.net/ projects/cantera/ and http://code.google.com/p/cantera/. Accessed 23 November 2011.

48. Healy, D.; Kalitan, D. M.; Aul, C. J.; Petersen, E. L.; Bourque, G.; Curran, H. J. Energy Fuels 2010, 24, 15211528.

49. NUIG Combustion Chemistry Centre, Natural Gas III mechanism, 2011. Available at http://c3.nuigalway.ie/ naturalgas 3.html. Accessed 23 November 2011.

50. Hong, Z.; Davidson, D. F.; Barbour, E. A.; Hanson, R. K. Proc Combust Inst 2010, 33, 309-316.

51. Pirraglia, A. N.; Michael, J. V.; Sutherland, J. W.; Klemm, R. B. J Phys Chem 1989, 93, 282-291.

52. Manion, J. A.; Huie, R. E.; Levin, R. D.; Burgess, D. R., Jr. ; Orkin, V. L.; Tsang, W.; McGivern, W. S.; Hudgens, J. W.; Knyazev, V. D.; Atkinson, D. B.; Chai, E.; Tereza, A. M.; Lin, C.-Y.; Allison, T. C.; Mallard, W. G.; Westley, F.; Herron, J. T.; Hampson, R. F.; Frizzell, D. H. Chemical Kinetics Database, NIST Chemical Kinetics Database, NIST Standard Reference Database 17, Version 7.0 (Web Version), Release 1.4.3, Data version 2008.12, available at http://kinetics.nist.gov/

53. Petersen, E. L.; Davidson, D. F.; Röhrig, M.; Hanson, R. K. In 20th International Symposium on Shock Waves 1996, p. 941.

54. Davidson, D. F.; Petersen, E. L.; Röhrig, M.; Hanson, R. K. Proc Combust Inst 1996, 26, 481-488.

55. Skinner, G. B.; Ringrose, G. H. J Chem Phys 1965, 42, 2190-2192.

56. Slack, M. W. Combust Flame 1977, 28, 241-249.

57. Bhaskaran, K. A.; Gupta, M. C.; Just, T. Combust Flame 1973, 21, 45.

58. Wang, B. L.; Olivier, H.; Gronig, H. Combust Flame 2003, 133, 93-106.

59. Masten, D. A.; Hanson, R. K.; Bowman, C. T. J Phys Chem 1990, 94, 7119-7128.

60. Du, H.; Hessler, J. P. J Chem Phys 1992, 96, 10771092.

61. Yang, H.; Gardiner, W. C.; Shin, K. S.; Fujii, N. Chem Phys Lett 1994, 231, 449-453.

62. Ryu, S. O.; Hwang, S. M.; Rabinowitz, M. J. J Phys Chem 1995, 99, 13984-13991.

63. Hwang, S. M.; Ryu, S. O.; De Witt, K. J.; Rabinowitz, M. J Chem Phys Lett 2005, 408, 107-111.

64. Shin, K. S.; Michael, J. V. J Chem Phys 1991, 95, $262-$ 273. 
65. Ashman, P. J.; Haynes, B. S. Proc Combust Inst 1998, 27, 185-191.

66. Mueller, M. A.; Yetter, R. A.; Dryer, F. L. Proc Combust Inst 1998, 27, 177-184.

67. Getzinger, R. W.; Schott, G. L. J Chem Phys 1965, 43, 3237-3247.

68. Getzinger, R. W.; Blair, L. S. Combust Flame 1969, 13, 271-284.

69. Blair, L. S.; Getzinger, R. W. Combust Flame 1970, 14, $5-12$.
70. Michael, J. V.; Su, M.-C.; Sutherland, J. W.; Carroll, J. J.; Wagner, A. F. J Phys Chem A 2002, 106, $5297-$ 5313.

71. Burke, M. P.; Chaos, M.; Ju, Y.; Dryer, F. L.; Klippenstein, S. J. Int J Chem Kinet, in press. DOI: 10.1002/kin .20603 .

72. Zsély, I. Gy.; Varga, T.; Nagy, T.; Cserháti, M.; Turányi, T.; Peukert, S.; Braun-Unkhoff, M.; Naumann, C.; Riedel, U. Energy, in press. DOI: 10.1016/j.energy .2012.01.004. 